\title{
The Role of selected signaling pathways and transcription factors in Chondrogenesis
}

\author{
Joseph A. Ayariga
}

The Biomedical Engineering Program, College of Science, Technology, Engineering and Mathematics (C-STEM), Alabama State University, 1627 Hall Street, Montgomery, AL, 36104; jayariga7546@myasu.alasu.edu

\begin{abstract}
During cartilage development, the lineage commitment and condensation of stem cells into chondrocytes and their differentiation involves a ubiquitous signaling cascades and huge numbers of transcriptional factors. The kinetic requirements and the stoichiometry for the expression of key transcriptional factors are relevant and must be met to form proper and functionally competent cartilage tissue. More interestingly also, an exact and precise spatio-temporal distribution of these molecules are as necessary in the proper tissue morphogenesis and patterning as the relevant physical conditions and micro environmental forces playing at the background during embryogenesis. A milestone of experimental achievements has been obtained over the years on several signaling pathways involved in cartilage development. Several fate determining transcriptional factors has also been investigated and determined with regards to the transition of stem cells (pluripotent, embryonic, etc.) into chondrocytes. These transcriptional factors serve as master controllers in chondrocytes proliferation and hypertrophy. Concerns that variability in signaling and transcriptional factors have detrimental effect on cartilage formation and could potentiate most cartilage related diseases have led most scientists to investigate the role of signaling molecules and transcriptional factors implicated in osteoarthritis, rheumatoid arthritis, and other cartilage degenerative diseases. On bases of spatio-temporal distribution of transcriptional factors, there exist functional overlaps, hence, it is difficult to draw a hard line of demarcation of roles at each point of the cell's life, nonetheless, it is also markedly established that some factors are skewed to the chondrocyte' survival and proliferation, and others known for their master's role in the cell's apoptotic, necrotic and senescence. Here we review some published works on selected signaling pathways and transcriptional factors that are preferentially expressed in chondrogenic cells and their role as major players in cartilage formation, cartilage diseases, along with some highlights of unique signaling molecules that are indispensable in cartilage tissue regeneration and management.
\end{abstract}

Keywords: Cartilage; transcriptional factors; Chondrogenesis

\section{Introduction}

\subsection{Structural Composition of $A C$}

Cartilage, an avascular tissue is a significant constituent of the connective tissues. This tissue is composed of dense matrix of collagen and elastic fibers embedded in grounded matrix produced by differentiated chondroblasts known as chondrocytes, and these all derived from the mesoderm during embryogenesis [1]. Most cartilage tissues are surrounded by perichondrium; a dense membrane that contains blood vessels and nerves and is noted to lie superficially on the articular cartilage. Nonetheless, most part of this tissue lacks blood vessels, especially the deep zone layer of articular cartilage (AC), and this unique nature provides a baffling mechanism as to how it regulates homeostasis, growth, and cellular differentiation. The chondrocytes been the cellular component of articular cartilage, they maintain very low proliferation in a nascent articular tissue, however in an adult articular tissue; chondrocytes are noted not to divide and are surrounded extracellularly with special constitution and organization of the matrix via a low-turnover replacement of key matrix proteins [2]. The articular cartilage is responsible for mechanical distribution of loads across joints. AC is layered into four zones which have each layer varying from the other in cellular morphology and density as well as ECM fibril formation:

The superficial zone: in this zone, chondrocytes have a flattened morphology with collagen fibrils parallel to the cartilage surface [3]. The presence of synovial fluid in this zone reduces friction between bones. More so, the zone contains type II and type IX collagen fibers with a characteristic high amount of collagen, fibronectin, and water 
in ECM which reinforces the tensile property of the matrix as well as resistance character against shearing and compressive forces on the articular surface [4].

The middle zone: composed of diagonally oriented fibrils that are randomly organized. This zone contains chondrocytes that are present in low numbers with spherical morphology and a high percentage of proteoglycan content, there is the presence of aggrecans in the matrix with perpendicularly arrayed collagen fibrils randomly distributed $[5,6]$.

The deep zone: the deep zone is characterized by cells and collagen fibrils that orients vertically and has a columnar morphology. In this zone, there is high amount of proteoglycan, absence of synovial fluid, and with a low amount of water hence providing for the greatest resistance to compressive forces [7], a partly calcified layer of this zone excludes vascular invasion and plays a role as interface between uncalcified region of cartilage and subchondral bone to provide structural integrity [4].

The calcified cartilage zone is a slender layer between the hyaline articular cartilage and the subchondral bone and is comprised of hard tissue that plays a great role in force transmission and nutrient diffusion [8]. This zone serving as an interchange, the mechanical stress and biological stimuli are transmitted from the hyaline cartilage to the subchondral bone through it. Additionally, this zone consists of type II collagen and hydroxyapatite, also with other organic and inorganic components, such as collagen X, calcium phosphate, and calcium carbonate [9].

\subsection{Types of Cartilage}

The physical characteristics of cartilage fall on the proportions of collagen fibers, elastin fibers and proteoglycan gel in the matrix [10]. There exist three different types of cartilage that plays different functions and are distributed slightly differently in the human body and these are hyaline cartilage, fibrocartilage, and elastic cartilage [11].

The hyaline Cartilage is noted to be the most abundant of the three; and is distributed in many parts of the body such as: the bronchi, the bronchial tubes, the costal cartilages, part of the supporting framework of the larynx, the housing of the nasal cavity, the supporting rings within the elastic walls of trachea, the coverings of the surfaces of bones at joints e.g., the ends of the long bones, and the anterior ends of the ribs. It also serves as the embryonic skeleton during embryogenesis. It has a pearly bluish-white tinge; the matrix appears amorphous and translucent or semitransparent, consisting of a dense network of very fine collagen fibrils and fibers embedded in proteoglycan gel with numerous chondrocytes and an ECM composed mainly of chondroitin sulfate [12]. Preponderances of skeletal elements are initially formed in hyaline cartilage; it also plays a critical role in determining the growth and development of several bones [13]. Hyaline cartilage tissue primarily provides smooth surfaces, facilitating smooth movements, flexibility, and support at joints.

The fibrocartilage: is a tough and strong tissue found predominantly in the intervertebral disks, calli, menisci, pubic symphysis and at the insertions of ligaments and tendons; it contains cartilage ground substance and chondrocytes scattered among clearly visible dense bundles of collagen fibers made up of Type I collagen within the matrix, and these bundles run linearly through the tissue, however, fibrocartilage lacks a perichondrium. This tissue provides support and rigidity to structures and is known to be the strongest of the three. The location of fibrocartilage do point to specific functions, for instance, intra-articular fibrocartilage of the menisci acts as buffers and spacers in joints with frequent movement and high impact; the connecting fibrocartilage of the intervertebral disks in limited-motion joints; the stratiform fibrocartilage in the thin coating of osseous grooves through which the tendons of certain muscles glide; and the circumferential fibrocartilage of the glenoid and acetabular labrum that surrounds the margins of some articular cavities hence deepening the articular cavities and protecting their edges [14, 15].

The Elastic Cartilage, this cartilage, also usually referred to as yellow elastic cartilage consist of a matrix dominated by a dense network of elastin fibers. This tissue provides support with moderate elasticity. It is found mainly in the epiglottis, the pinna, and the Eustachian/auditory tube [16]. In elastic cartilage, the chondrocytes are located in a threadlike network of elastic fibers within the matrix of the cartilage; also, there is the presence of a perichondrium. Elastic cartilages provide support and maintenance of shape to surrounding structures [17]. It 
usually is not exposed to high mechanical loads, or prolonged mechanical stress, hence, the damages associated to this tissue is rare relative to the other types of cartilage [18].

\subsection{Cartilage and associated diseases}

Due to a low metabolic activity and slow nutrient diffusion within cartilage, damage to this tissue often inevitably consist of slow and delayed regeneration and healing, the restriction of blood from reaching most part of this tissue and the resultant limitations in the availability of oxygen and other essential amino acids dictates a very slow systemic metabolic response since transports system employs less speedy forms such as transport proteins across the thick ECM. Accidents that cause injury to the knee may sometimes rupture the articular cartilage. Most diseases associated to AC include the following: 1) Osteoarthritis (OA); a condition where the cartilage covering the bones in joints is thinned and sometimes completely worn out. This leads to exposure of the bone ends to friction and erosion which causes bone damage. Aberrant immuno-metabolism has been implicated in most phenotypes of OA, since metabolism usually in this condition is drastically altered [19].

2) Rheumatoid arthritis (RA) is a chronic systemic autoimmune disease that primarily affects the lining of the synovial joints. This disease is progressive with the pathological mechanism driven via the deterioration of cartilage, bone erosion, hyperplastic synovium, and systemic consequences [20]. Most symptoms of RA include arthralgia, swelling, redness, joint pain and hence limiting the range of motion [21].

3) Relapsing polychondritis (RP); is an immune-mediated systemic disease characterized by recurrent episodes of inflammation of cartilaginous and proteoglycan-rich tissues, resulting in progressive anatomical deformation and functional impairment of the involved structures [22]. This is usually located in the ears, nose, throat, heart valves, joints, rib cage and sinuses. This complex disorder is known to involve both humoral and cell-mediated immune systems. Autoantibodies against collagens II, IX and XI have been reported in RP patients, implying that cartilage-specific autoimmunity is a crucial player in the disease progression of RP [23].

4) Achondroplasia usually leads to dwarfism and is a condition where the chondrocytes within the cartilage fail to proliferate and the epiphyseal plate of long bones near the joints are particularly affected hence limiting bone growth and development. The disease etiology is said to be genetic and arises from dominant autosomal mutations [24].

5) Other important diseases worth mentioning include costochondritis which is associated with the ribs [25, 26], herniation which is concern with the rapture of the cartilaginous disc between vertebrae disc [27], malignant and benign tumors of the cartilage called chondrosarcoma [28] and chondroma [29] respectively.

\subsection{Limb organogenesis and chondrocytes origin and lineage}

Limbs and all their associated parts are derivatives of a host of sophisticated sequence of interactions between tissues derived from the three distinct germ layers. At the commencement of limb formation, lateral plate mesoderm is induced to grow and form limb buds [30] in which the mesenchymal cells in the presumptive limb fields are activated to proliferate while the flanking somites are slightly inhibited from rapid proliferation [31]. Following this event, cells from the lateral edges of the adjacent somites migrates into the limb to form limb muscles [32]. Hence, at embryogenic development, the embryonic tissues surfaces such as the ectoderm, somatopleural mesoderm, neural crest cells, somites, hematopoietic cells collectively form the limb bud [33]. 


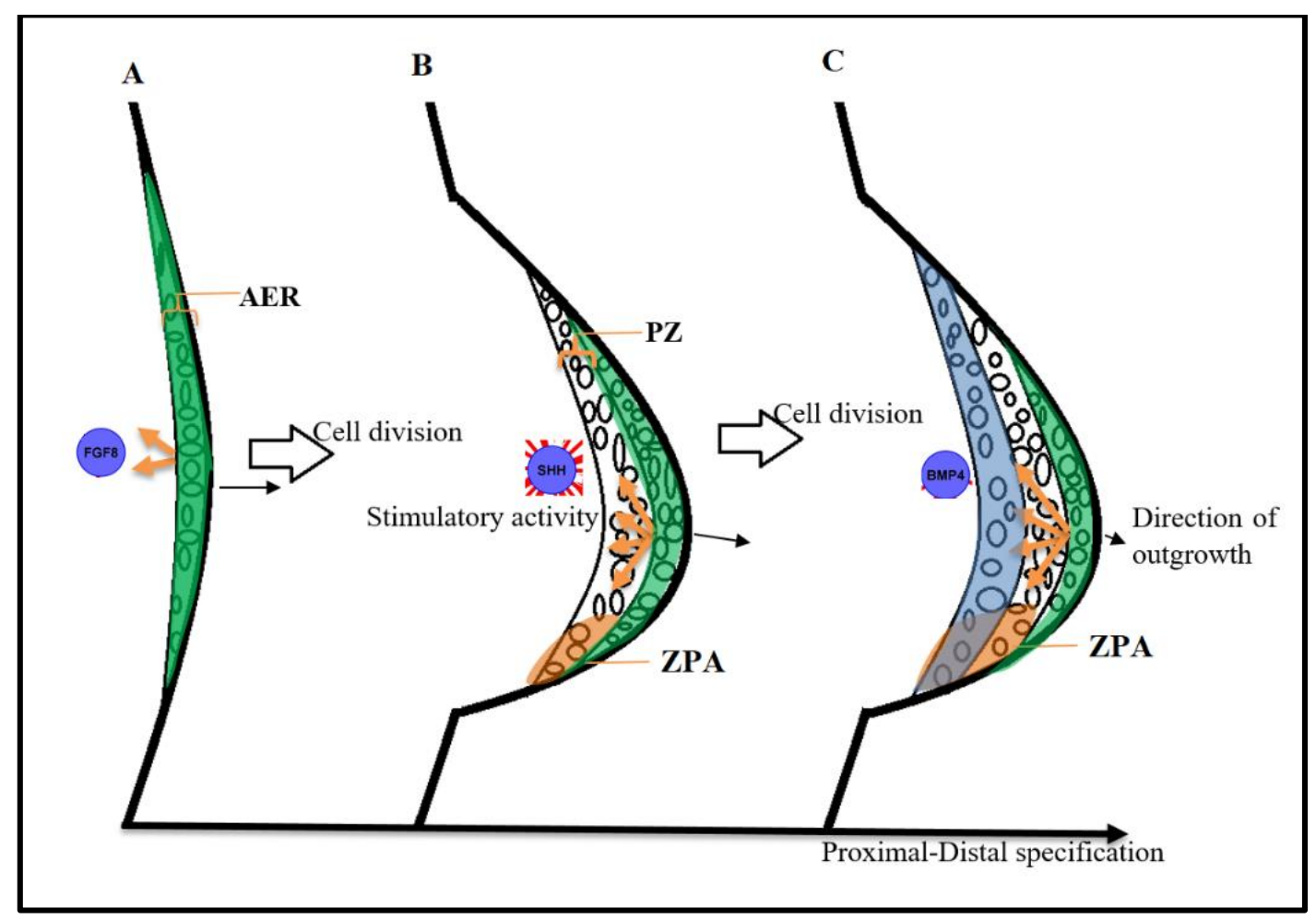

Figure 1. Diagrammatic illustration of the Limb bud organogenesis; showing the Progress Zone Model.

A) Apical ectodermal Ridge (AER) stimulated by signals and morphs to obtain an elongated form as in B), most of the signaling of the AER is noted to have been FGF8, however it is worth noting that is far much complex than a single signaling molecule. B) Formation of progress zone (PZ), and continual influence of AER signals to form proximal distal orientation. Here, preponderance of molecular signaling is demonstrated to be Sonic Hedgehog $(\mathrm{SHH})$, however, as shown in $\mathrm{D})$, the interaction of $\mathrm{SHH}$ with other signaling partners are far more complex. Here, a zone of polarizing activity (ZPA) is formed. C) Proliferation of cells in the progress zone (PZ), they are displaced proximally, and under the direction of intrinsic cues they still retain their positional address even though displaced. Increase influence and are of ZPA is present at this stage. 


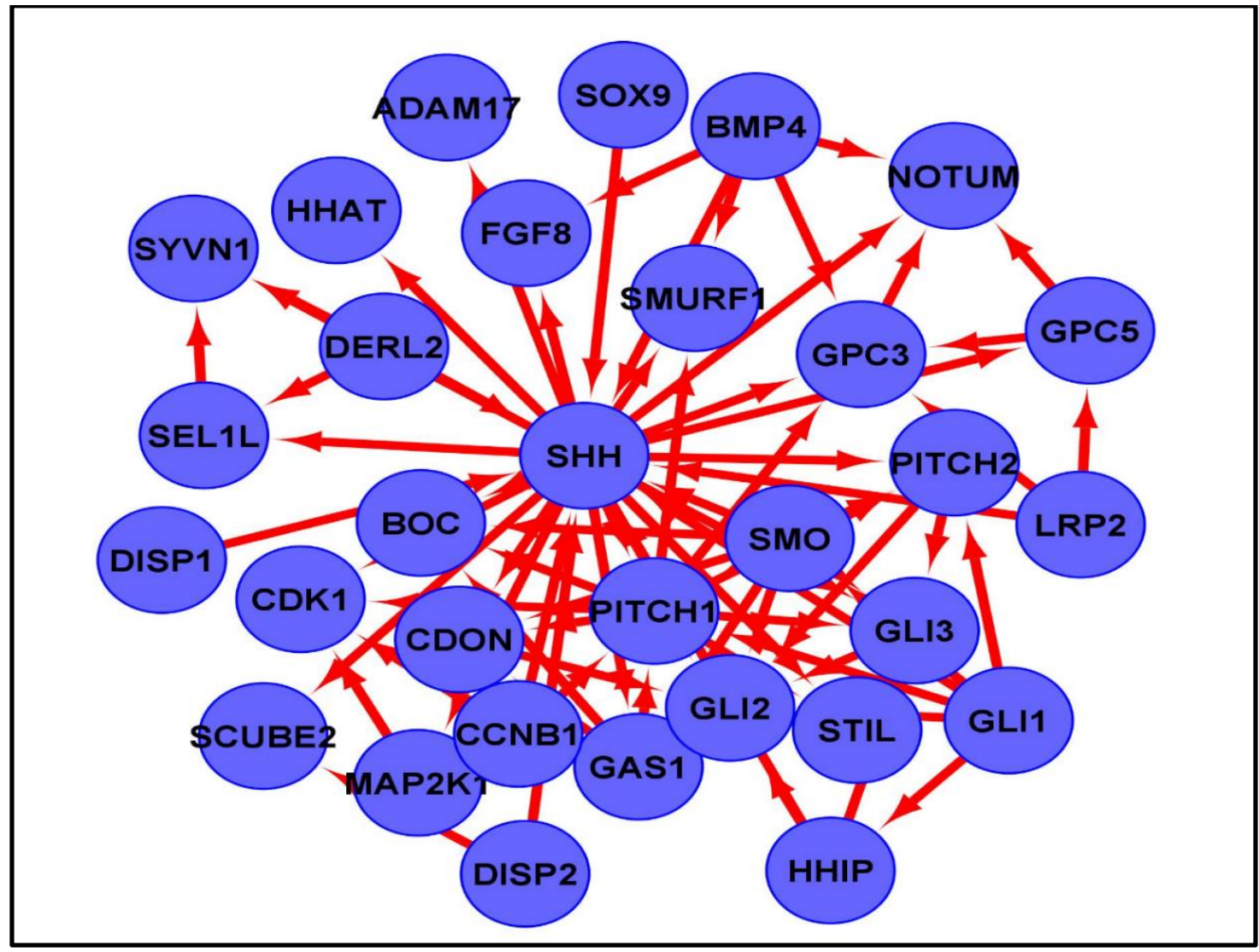

Figure 2. A simplified string network of SHH signaling, and interaction with other signaling partners. Retinoic acid, though not captured here, has also been demonstrated to have a significant role in limb bud initiation [34]

The three spatial axes along which limb development and patterning follows is directed via three well-characterized signaling centers that are well coordinated. As the apical ectoderm ridge (AER) directs the proximal-distal limb outgrowth; the zone of polarizing activity (ZPA) patterns the limb along the anterior-posterior $(\mathrm{A} / \mathrm{P})$ axis; while the non-AER limb ectoderm sets up the dorsal-ventral (D/V) polarity $[35,36]$. These signals are then integrated to form the spatial pre-pattern field for the limb mesenchyme, and as well as other cell types to be specified [37].

Mechanical, molecular, genetic, morphological, and other factors play critical role in shaping and patterning these tissues into their definitive structures, and therefore no single factor could solely be responsible for any outcome. For instance, the proximo-distal axis is because of the induction of the apical ectodermal ridge, for which the Hox [38] and the FGF families and their respective receptors have been implicated to show crucial role in the modulation, regulation and direction of axis morphogenesis and positional identity [39,40]. The classical progress zone models predict that the acquisition of identities along the proximodistal (PD) axis depend on the time the mesenchymal cells spend under the influence of the AER [39]. Also, the Sonic hedgehog (SHH) molecules has been showed to fashion the gradient of concentration that differentiates the future antero-posterior derivatives [41, 42]. Similarly, the Wnt7a [43] and Lmx1 [44] have been implicated in the ventro-dorsal axis morphogenesis specification, while the Engrailed 1 gene directs ventral specification $[45,46]$. The well-researched Wnt signaling pathway controls gene expression by stabilizing $\beta$-catenin and regulates a host of developmental processes [43].

\subsection{Morphogenetic mechanisms of Joint and cartilage formation}

The organogenesis of joints during embryogenesis is a well-studied subject [47], for which the emergence of characteristic features of joint anatomical structures on a developmental time scale noticeably distinguished and has been mapped and well documented [48]. The joint elements anlages are noted to be complete during the embry- 
onal period for which during this developmental time frame, the cartilaginous anlages condense to form avascular tissue at the interzones [49]. The obvious question that readily come to mind is what signal information resident cells at the interzone have received/or previously contained that cause their condensation and subsequent morphological changes. Tabin and Wolpert postulated that cells under the influence of the AER remain undifferentiated but induce distal fates upon the cells leaving the influence of the AER [50], and this might hold true for the homogeneity in undifferentiated cells prior to condensation to form the interzone. More so, Canonical WNT signaling has been demonstrated to interact with the AER-expressed FGF signals to keep the distal cells in a proliferative, undifferentiated state [51]. In conformity with this proposition, the Cells outside the influence of these signals withdraw from their undifferentiated state and begin expressing Sox9 and possibly other chondrogenic genetic markers to undergo chondrogenesis having received instructive information from the FGFs that induce distal fates [38]. The path to developing skeleton and its associated elements such as cartilage and ligaments in early embryonic limbs consists at first of an interrupted condensed mesenchymal structure; the interzone, which consists of close group of mesenchymal cells connected by gap junctions [52] with the adjacent condensed mesenchymal cells differentiating into chondrogenic elements [53]. With passing developmental time, the interzone morphs in size, producing chondrogenic progenitor cells that are apposed at each of the epiphyseal end [49]. These differentiating cells with others taking part in the morphogenetic processes mold the opposing interlocking sides of the joint and eventually producing the articular cartilage and other components including ligaments $[49,52,54]$.

\subsection{Importance of mechanical mechanisms in Joint and cartilage formation}

How mechano-signaling process is initiated through cell-matrix interactions and transmits mechanical signals from the matrix, through chondrocyte mechanoreceptors activation on the cell surfaces to effect intracellular responses has been investigated [55], though, a comprehensive understanding of the full scale of mechano-signaling has not been obtained. Yet it so far understood that multiple signaling cascades are regulated by mechanical load, and thus contribute to the maintenance of cartilage homeostasis. Therefore, mechanical processes play a crucial role in the morphogenesis of the $\mathrm{AC}$ as a unit and the entire joint as a whole $[56,57,58,59,60]$. The physical mechanics that could have driven the initial mesenchymal cell condensation to form the interzone is not well unexplored [59], although later events of synovial cavitation and superficial cartilage zone has been noted to have a mechanical force as an added dimension with all the other factors that drives joint formation and AC morphogenesis [60]. For instance, the formation of the superficial zone of AC, the synovial cavity, as well as the synovial fluid is said to be driven by muscle movement [54], a study with muscle deficient mice indicated the lack of proper formation of the superficial zone of the AC [61], as well as an absence of joint cavity and synovial fluid in the joint $[54,61]$.

To this end, the spontaneous, slightly random, and spasmodic movements observed in developing fetus cannot be counted as haphazard occurrences, but rather mechanistic stimuli directed to specific sites of the developing embryo. While the molecular mechanisms directing the morphogenesis of the joint, the formation of the AC and all the associated tissues have been well described [62, 63, 64], only in recent times are researchers beginning to invest the much-needed research effort on mechanochemical coupling as another factor directing organogenesis [65]. This later aspect has come due in part to the burgeoning field of tissue engineering and regenerative medicine as the demand to understand the biomechanics of these tissues are required in tissue scaffold designs [66]. While it is now certain that mechanical forces play a crucial role in signaling tissue organization, cell differentiation, organ patterning [54], much research is needed to fully elucidate the specific regulatory inputs mechanical forces induce on proliferating, differentiating, or mass organizing and patterning tissues. For instance, do mechanical forces induce the formation of stiffness of the cartilage, and on what spatio-temporal dimension are such inputs critical to proper formation of these structures? And yes, while we have anecdotal answers to these questions [60, 54, 67], the specifics are a must if such understanding is to be used in therapy/disease management plans. Mechanical forces are rapid and cover an expanse of tissue volume at once compared to chemical cues, hence mechanical factors might serve to direct collective cell processes e.g. proliferation, apoptosis, enzyme synthesis, or condensation as typified by the early processes in the formation of the interzone. At the intracellular level, mechanical forces derived from microfilament dynamics might regulate specific genes expressions [68], e.g. the upregulation of collagen type II expression in the middle zone to increase cartilage stiffness, while lubricin and hyaluronans are highly expressed by chondrocytes residing in the superficial zone which serve to increase fluidity 
and hence decrease friction on the cartilage surface all has special bearing to mechanical load bearing and force transmission principles.

The importance of understanding the mechanical factors goes beyond just understanding their effect on development of the nascent fetus' structures, but most certainly the application of such knowledge to advancing the much-needed therapeutics and management methods required for bone and cartilage related diseases. One major disease of the cartilage being OA usually leaves scars on the superficial cartilage at mild conditions, but deep grooves of wounds or entire erosion of the superficial and middle zone hence making it a painful experience for patients to walk [66], since walking inevitable implies exerting load on such wounded surfaces. However, in normal cartilage, the tissue surface is smooth and "greased" by the synovial fluid such as lubricin and hyaluronans making load bearing an easy and efficient task. Scar tissue therefore in such location will unavoidably interfere with the smooth surface and would have deleterious consequences to the AC. Unquestionably, an advanced understanding of the mechanism of re-epithelialization of wounds that occurs in embryonic skin wound healing will go a long way to help design and target therapeutics and management methods for OA. Recent study using an in vitro AC wound model, demonstrated that the chondrocytes of the superficial zone rapidly proliferated and surrounded the injured cartilage in manner mimicking the re-epithelialization of wounds [69, 70].

In this perspective, integrating biomechanical comprehension of chondrogenic tissue development with the indepth understanding of the morphological, molecular, and homeostatic concepts of articular cartilage can be deployed as a feasible model for cartilage regeneration.

\subsection{Selected Signaling pathways and transcriptional factors crucial for cartilage formation}

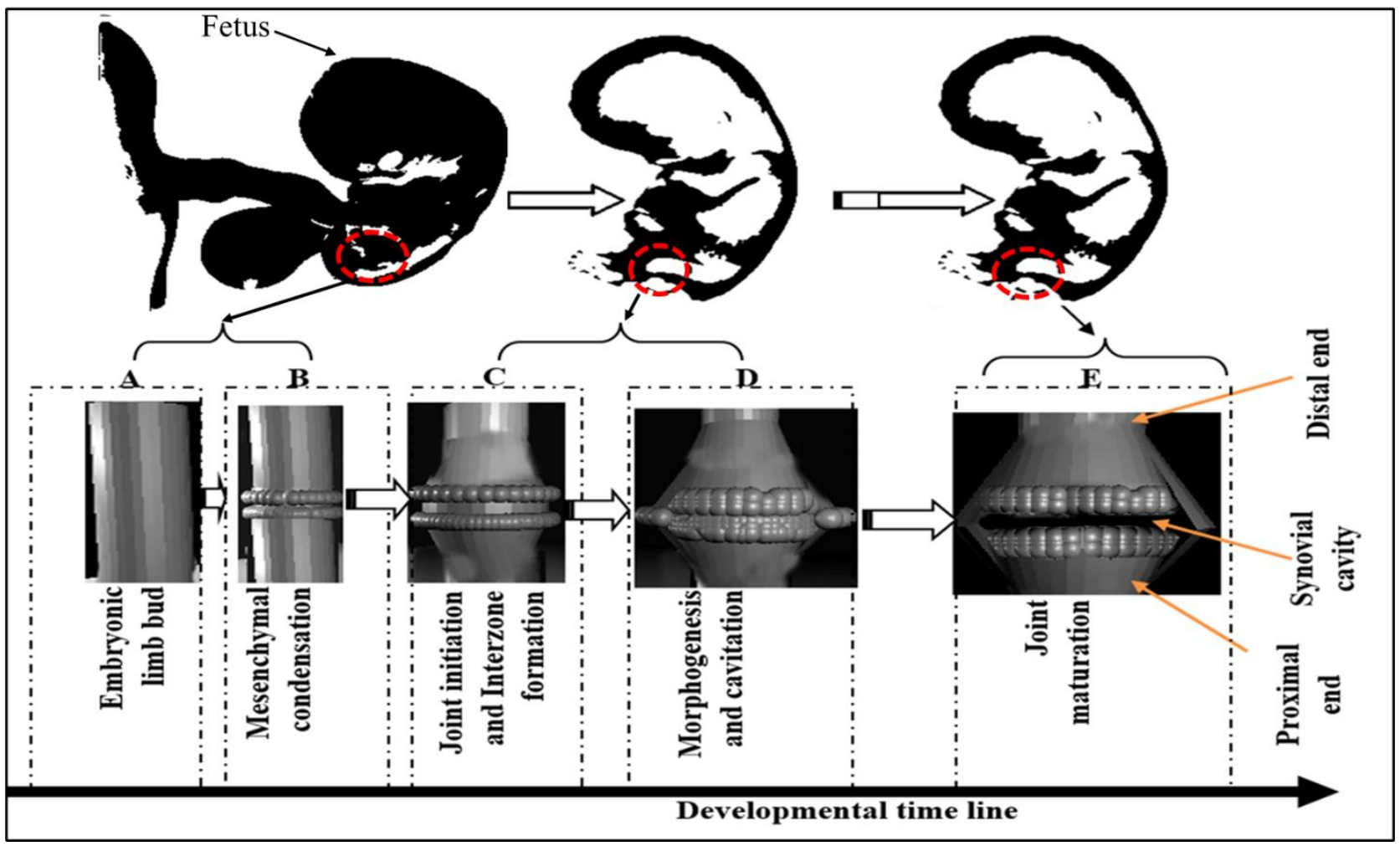

Figure 3. Diagrammatic representation of the developmental journey of the joint in a fetus; Figures not drawn to scale. 


\subsection{Wnt Signaling pathway and its implication on cartilage development}

Scientific investigations have demonstrated the involvement of the Wingless-type mouse mammary tumor virus (MMTV) integration site (Wnt) in processes as diverse as segmentation, CNS patterning, control of asymmetric cell divisions [71], and including in axis patterning specification [72]. Wingless-type mouse mammary tumor virus (MMTV) integration site (Wnt) signaling has been shown to play a very crucial role in chondrogenic and osteogenic tissues development [43]. The cartilage morphogenesis is shown to incorporate several signaling pathways, among which, Wnt signaling contributes to varying developmental aspects [73]. The Canonical Wnt signaling is mediated mainly by $\beta$-catenin protein, a multitasking protein; in addition to other potent co-activator of transcription factors such as lymphoid enhancer factor (LEF) and T-cell factor (TCF) [43, 74, 75]. This pathway leads to an accumulation of $\beta$-catenin in the cytoplasm and its eventual translocation into the nucleus to act as a transcriptional coactivator of transcription factors that belong to the TCF/LEF family [43, 75]. Wnt Signaling pathway is one of the highly studied signaling pathways and is noted to be conserved $[43,73,74,75,76]$. Accumulation of $\beta$-catenin is achieved via the inhibition of this molecule from proteolytic degradation via the Wnt signaling process [71]. The propagation of this signaling is initiated by the binding of Wnt proteins to specific receptors on the surface of the chondrocyte or progenitor cells, usually a transmembrane frizzled proteins and a LRP5/6 [71, 77, 78]. Binding induces the recruitment of the cytoplasmic protein disheveled (Dvl) leading to its activation, then activation of Dvl causes the GSK-3 $\beta$ from Axin complex to dissociate [43, 72]. Usually, it is this complex that causes the phosphorylation and subsequent degradation of $\beta$-catenin in the cytoplasmic milieu. Now out of the way, $\beta$-catenin is no longer phosphorylated and hence not proteolysed, leading to the accumulation of this molecule in the cytoplasm as depicted in Figure 3. Translocation of $\beta$-catenin into the nucleus occurs subsequently leading to the target genes expression [43]. Dysregulation of $W n t / \beta$-catenin signaling has been highlighted as causes of several degenerative diseases [43], and an important factor in tumorigenesis [77, 78]. 


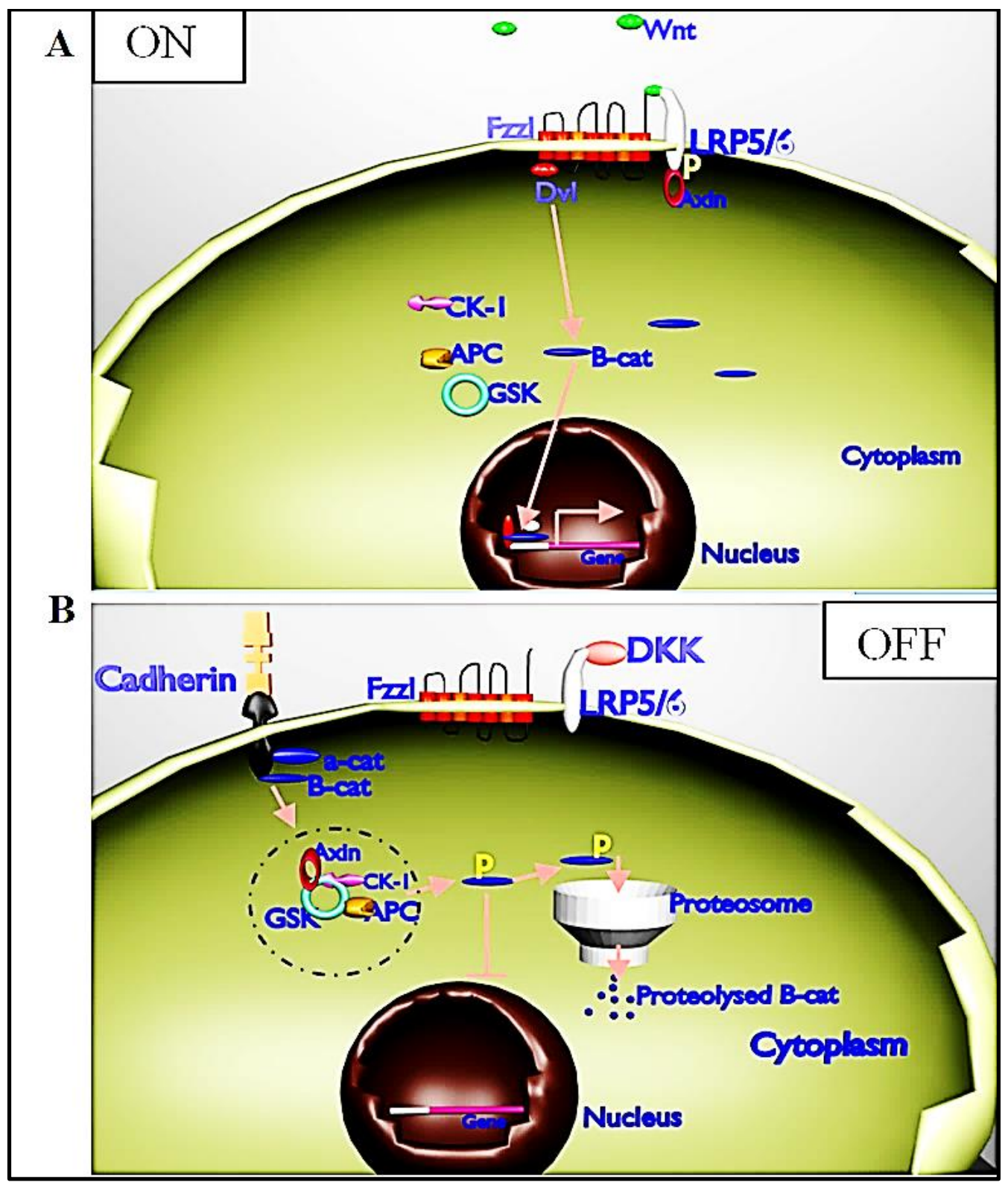

Figure 4. Diagrammatic depiction of the Canonical Wnt/B-catenin signaling pathway

The canonical wnt signaling pathway, the on state as indicate in $\mathrm{A}$, and the off state as indicated in $\mathrm{B}$. As shown in $\mathrm{A}, \mathrm{Wnt} / \mathrm{b}$-catenin pathway is propagated through the trans-membrane frizzle (fzzl) receptor and the disheveled $(\mathrm{dvl})$ intracellular molecule. This brings about inhibition of axin, glycogen synthase kinase $3 \beta$ (GSK3 $\beta$ ), adenomatous polyposis coli (APC), casein kinase 1 (CK-1) complex from forming. This complex induces the phosphorylation of $\beta$-catenin and subsequent ubiquitination degradation of the molecule, and since the complex is not formed, accumulated $\beta$-catenin is eventually translocated into the nucleus where it binds to T-cell factors (TCF)/ Lymphoid enhancer binding factors (LEF), thereby activating the transcription of target genes. However, when the pathway is off, as shown in B, $\beta$-catenin is induced to phosphorylate by the axin, GSK3 $\beta$, CK- 1 complex, next phosphorylated $\beta$-catenin is targeted by proteasome and degraded.

Canonical Wnt signaling has been shown to sustain high levels of FGF10 expression during limb initiation also in the mouse [79], Wnt10a a member of the Wnt family is demonstrated to be expressed in chick limb ectoderm and induces FGF8 through the same pathway [80]. Unexpectedly, it seems that not all the family members of Wnt operates similarly or produces similar effects, for instance, Wnt 4 has been reported to accelerate chondrocyte maturation, whereas the Wnt5a delays differentiation of chondrocytes via hypertrophy [80]. Hartmann and Tabin also reported that that Wnt-5a, Wnt-5b and Wnt-4 genes were expressed differentially with respect to spatial 
pattern of the developing limb: whereas Wnt-5a was shown to be expressed in the perichondrium, Wnt-5b was expressed in a subpopulation of pre-hypertrophic chondrocytes and in the outermost cell layer of the perichondrium, and Wnt-4 was expressed in cells of the joint region [80].Wnt9a or $\beta$-catenin deficiency has been linked to disappearance of Gdf5 expression and a reduction of joint formation [81], fused joints [82] joint degenerative diseases such as rheumatoid arthritis [83]. Increased Wnt8a and Wnt16 in the synovium has been implicated in the progression of OA through increased production of MMPs, which are the major protein involved in cartilage degradation [84]. In OA experimental mice, canonical Wnt pathway activation led to the formation of osteophytes [85]. Genetic suppressing of $\mathrm{Wnt} / \beta$-catenin activity resulted in osteoarthritis via the mineralization of subchondral osteoblasts [86]. These reports highlight a few of the importance of $\mathrm{Wnt} / \beta$-catenin signaling in joint development and cartilage and bone formation.

\subsection{The BMPs signaling pathway}

Bone morphogenetic proteins (BMPs) and Wnts signaling protein families are conserved pathways, each independent of the other and yet have unique specific extra- and intra-cellular molecular interactions and crosstalk that occur between them, depending on the cell type [87]. While we have defined and discussed Wnts above, BMPs on the other hand are cytokines with multi-functional properties, belonging to the transforming growth factor- $\beta$ (TGF- $\beta$ ) superfamily.

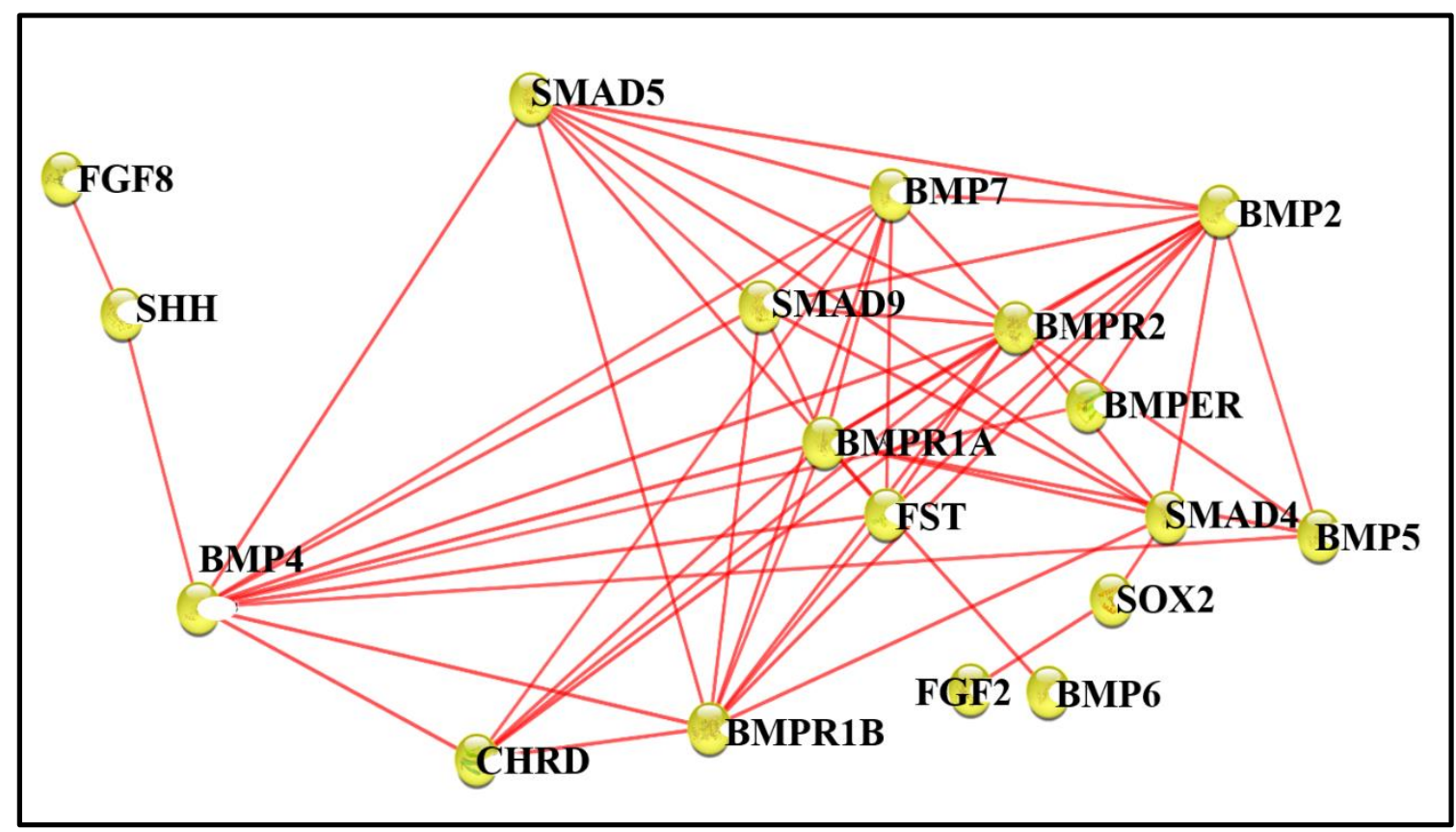

Figure 5. String Style Interaction Network Map of BMPs signaling created using cytoscape 3.8.1

BMPs are low molecular weight glycoproteins, e.g. recombinant human Bone morphogenetic protein-2 (rhBMP2) has a molecular weight of $26 \mathrm{kDa}$. Through recombinant gene technology, rhBMP-2 has been engineered for research and clinical trials for bone diseases and cartilage regenerative therapies [88]. Seller and co. demonstrated in a clinical case that the addition of rhBMP-2 to the operative site after creation of a full-thickness defect resulted in an improvement in the histological appearance and composition of the extracellular matrix after one-year postoperation [88]. The hrBMP-2 has been demonstrated to induce structurally sound orthotopic bone in femoral defects in rats, tibial and ulnar defects in rabbits, femoral defects in sheep, mandibular defects in dogs, spinal fusion in dogs, and porous ingrowth in rats $[88,89]$. With approximately 15 BMP family members, they signal by coupling with three transmembrane type II receptors and four transmembrane type I receptors. The binding of BMP activates the phosphorylation type I receptor by the type II receptor. This initiates a cascade of intracellular signaling that is started by phosphorylation of receptor-regulated SMAD1/5/8 [90]. This complex binds later with SMAD4, leading to transcriptional responses of specific gene targets. There are feedback regulatory mechanisms 
enabling crosstalk with other signaling pathways [91]. BMP plays crucial roles during embryonic skeletal development, which include mesenchymal condensation and chondrogenic differentiation of MSCs, BMPs induction of early cartilage formation through chondrocyte proliferation and maturation and endochondral ossification [92]. BMPs have been shown to regulate endochondral ossification by promoting chondrocyte proliferation and inducing chondrocyte hypertrophy [93, 94]. These morphogens have also been demonstrated by Varady and his colleagues, using computed tomography and radionuclide imaging study of BMP-2 gene therapy, to regulate bone homeostasis via osteogenic and chondrogenic potential modulation [95]. They have been postulated to have protective functionality for articular cartilage and on the flipside however, BMPs can pose deleterious effects on $\mathrm{AC}$ by inducing chondrocyte terminal differentiation and contributing to OA progression [96].

\subsection{FGF signaling}

Almost half a century ago, the fibroblast growth factor (FGF) was discovered [97, 98]. Initially identified in the pituitary to affect mitogenic activity, later scientific investigations produced a body of evidence that demonstrated that FGFs also affect cell proliferation, differentiation, survival, and motility [99, 100]. Narrowing down to specifics, different members of the FGF family has been profiled to play varying critical roles such as intercellular signaling in embryogenesis [101], chondrogenesis and osteogenesis [102]. Currently, there exist 22 mammalian Fibroblast Growth Factors (FGFs) that interact with four signaling tyrosine kinase FGF receptors (FGFRs) [103]. Individual FGFs found in vertebrates and invertebrates are related by core sequence conservation and structure [104, 105]. These 22 FGFs have been phylogenetically categorized into 7 subfamilies, each subfamily consisting of 2, 3 or 4 members. FGFs have been shown to be positive regulators of chondrogenesis [103], playing roles in the right patterning of developing cartilage [103].

The canonical FGF signaling is carried out by the following subfamilies genes; Fgf1, Fgf4, Fgf7, Fgf8 and Fgf9, which activate FGFRs in the presence of Heparin (HS) cofactor [103]. The Fgf9 subfamily genes consist of Fgf9, Fgf16 and Fgf20, whereas the Fgf7 subfamily genes are the Fgf3, Fgf7, Fgf10 and Fgf22. The two other subfamilies' genes within this canonical FGFs are the Fgf4 and Fgf1 which are comprising of the genes Fgf4, Fgf5 and Fgf6 for the Fgf4 classification, and Fgf1 and Fgf2 for the Fgf1 subfamily respectively [103, 106].

The endocrine FGFs consist of three members encoded by the Fgf15/19, Fgf21 and Fgf23; these are secreted endocrine signals that act on distant target cells via the FGFR-heparan sulfate (FGFR-HS) complex and FGFR-Klotho complex. On the other hand, the last subfamily of FGFs (all under the umbrella of Fgf11 subfamily) are grouped under the intracellular FGFs, and are encoded by Fgf11, Fgf12, Fgf13, and Fgf14 genes. These intracellular FGFs encodes for non-signaling proteins that operates as cofactors for voltage gated sodium channels and other proteins [107]. Usually, FGF signaling is achieved via signal molecule binding to a cofactor and the appropriate receptor, and these receptors are known as the FGF-receptors (FGFR). FGFRs are tyrosine kinases that are structurally composed of extracellular, transmembrane, and intracellular domains. The extracellular domain is immunoglobulin-like and sits on the surface of the cell membrane, while the transmembrane domain is embedded in the membrane, the intracellular domain is a two tyrosine kinases domain protruding into the cytosol and latching to the inner side of the membrane via the transmembrane attachment. The immunoglobulin-like extracellular domains of the FGFRs have spliced variants that are necessary in specifying ligand-binding specificity [103, 106]. The specificity and affinity of the FGF ligands to their receptors are said to be affected when FGF ligands interact with ECM during FGF molecules diffusion through tissue prior to ligand-receptor interaction [108] and both synergistic and antagonistic effects on overall FGF signaling have been reported [109, 110, 111]. 


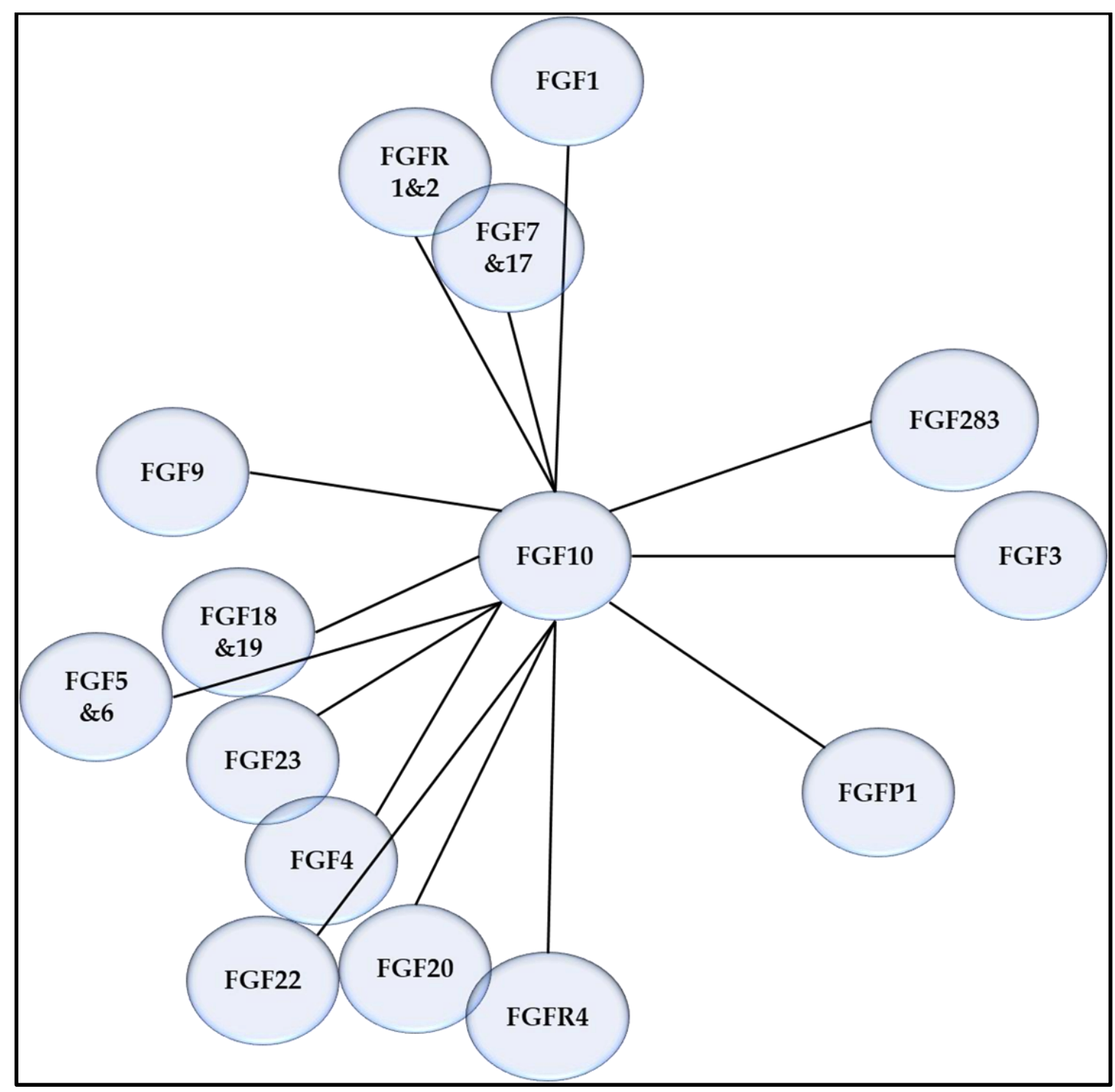

Figure 6. Prefuse Force Directed OpenCL layout map of FGF10 interaction with other FGFs created using cytoscape 3.8.1 compiled using PubMed PDB

During embryogenesis, limb development is initiated by an outgrowth called the limb bud which begins with an observable apical ectodermal ridge (AER) and the bud mesenchyme. It is clear that specific sites of the developing limb, especially the zone of polarizing activity (ZPA) and the AER play a critical role in the patterning and growth of the limb during embryogenesis [103, 107], the synthesis and distribution of FGFs has been shown to be partly limited to the AER [112], especially FGFs such as the FGF2, FGF4, FGF8 and FGF9 [113, 114]. Even though other molecules such as retinoic acid (RA) have been reported to orchestrate limb bud development [115], recent studies debunk such proposition in favor of rather an indirect regulatory role in which it limits the concentrations of FGFs in specifics areas of the developing bud [107]. The proximal RA production in ZPA has an antagonistic effect on distal FGFs production at the AER, and this is thought to control the progression and proper patterning of the proximal-distal axis of the developing limb [107]. RA is demonstrated to specifically limit the distribution of FGF8 [116].

FGF2, FGF4 and FGF8 are important regulators of P-D growth [117], and FGF2 has been demonstrated to prime mesenchymal stem cells for chondrocytic differentiation [118, 119]. While induction of chondrogenesis usually activates Sox9 gene, an inactivation of TGF- $\beta$ signaling and IGF-1 has been observed in several published findings [118, 120]. FGF2 has a role in bone mineralization, wound healing, and skeletal development [120]. FGF2 enhances the speed of chondrocyte proliferation as well as primes prochondrogenic cells for terminal differentiation 
[9], the induction of differentiation has been shown to be achieved via the down regulation of TGF- $\beta 2$ by the FGF2 [120], however, an up regulation of TGF- $\beta 1$ expression by FGF2 has been linked to the acceleration of chondrogenic cell proliferation [121]. In a synergistic investigation in which both TGF- $\beta 3$ and FGF2 were studied; a concurrent presence of both TGF- $\beta 3$ and FGF2 gave interesting results, first, a null effect on proliferating chondrocytes was observed, second, no inhibition of differentiation was observed in prechondrogenic cell transition to chondrocytes, however, chondrocytic hypertrophy was completely inhibited [122]. In another synergistic study, FGF2 in combination with Wnt3a or platelet-derived growth factor (PDGF) or Insulin/TGF- $\beta 1$ led to a functional cartilage production [123, 124]. These referenced investigations highlight the important role FGF2 play in chondrogenesis and cartilage development as well as limb organogenesis. First to be identified as early as 1973, the protease sensitive and thermolabile FGF2 was finally purified to homogeneity in 1983 [125] and was then coined basic FGF (bFGF) and recently grouped into the Fgf1 subfamily of the canonical FGFs [107]. The mechanism of action of this subfamily (Fgf1 and Fgf2) has been hypothesized to follow a process in which the signaling molecule can be translocated directly across cell membrane [126] in direct contrast to the need for a receptor as in the usual phenomenon of all the remaining canonical Fgfs signaling [107]. This translocation is thought to be achieved via the assistance of a chaperonic complex [127, 128], implying that the molecule could move through the membrane into the cytoplasm and transverse the cytosol into the nucleus to potentiate the transcription of specific target genes or control cell differentiation, survival, and apoptosis [129, 130].

FGF9 has been shown to positively up regulate prochondrogenic processes, or even tow towards osteogenesis. The direction of mesenchymal cell's fate controlled by this signal is said to depend on the expression levels of the molecule as well as the population of cells [131]. FGF9 has been demonstrated to drive hypertrophy [132], vascularization of growth plate prior to osteogenesis [19], up regulation of Sox9, IHH, FGF9 and Col2a1 genes expressions [121]. Interestingly, FGF9 has also been shown to positively upregulate proosteogenic proteins such as Col10a1 [121]. FGF18 has been proven to stimulate repair of damaged cartilage [133]. Since it has been established that FGF signaling modulates development limb bud, the crucial mesenchymal condensation during joint formation, chondrogenesis, osteogenesis, bone mineralization and homeostasis, an understanding of the mechanisms and functions of the FGF signaling pathway during critical stages of skeletogenesis, will informs us of the links between FGF signaling pathways and cartilage degenerative diseases and the exploitation of such knowledge for cartilage disease therapy such as the management of OA or injury to the cartilage during accidents.

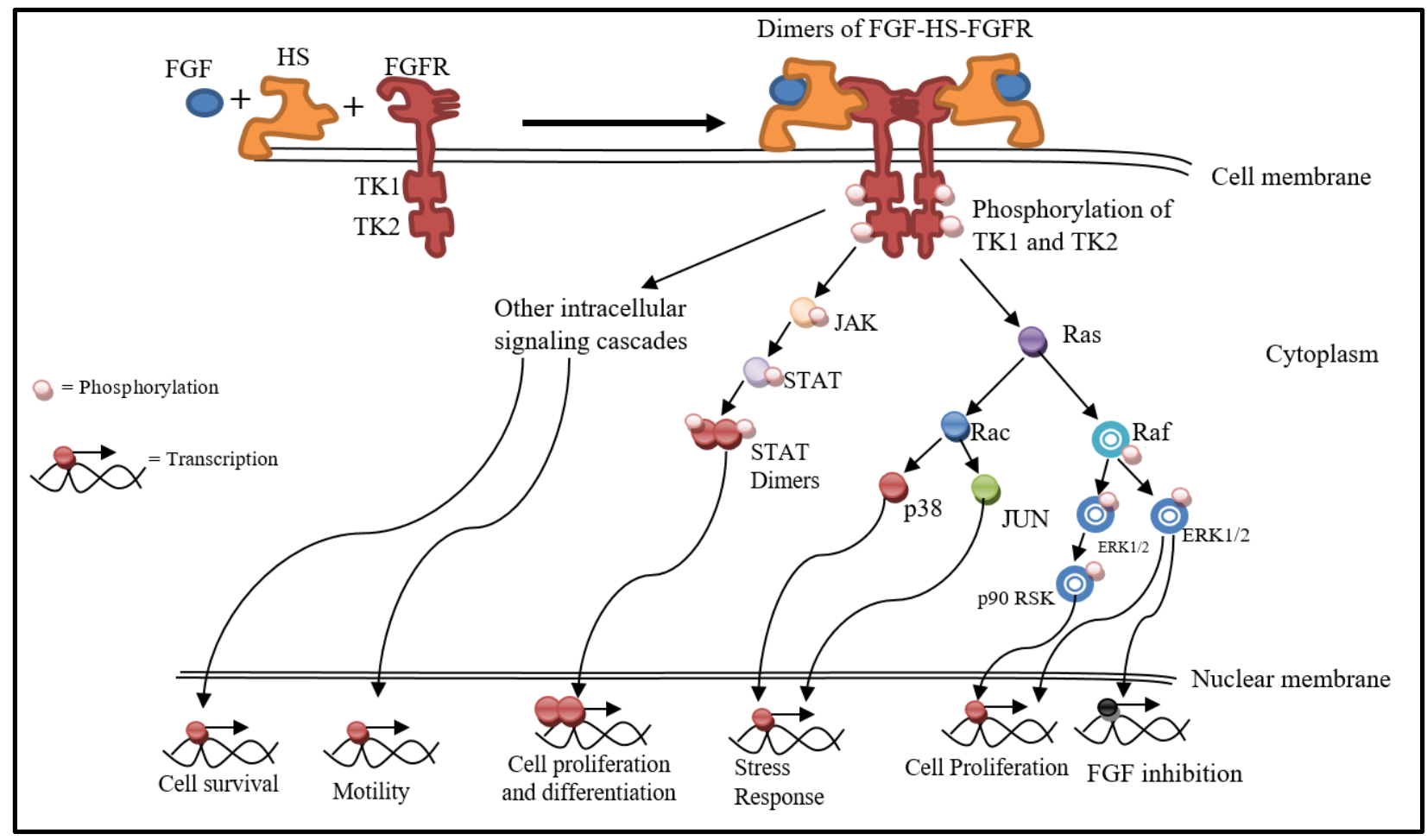

Figure 7. Illustrating the FGF signaling pathways. 
Diagram of fibroblast growth factor (FGF) signaling; the canonical pathway indicates a mechanism in which two FGFs signal molecules find and bind to Heparin sulfate (HS) molecules, these complexes further binds to two FGFRs on the surface of the cell membrane, causing them to dimerize. The FGFR is composed of 3 domains; the outer/extracellular immunoglobulin-like domain, the transmembrane protein, and the intracellular domain; the intracellular domain functions as a tyrosine kinase. Binding of FGF to the FGFR and subsequent dimerization causes the activation of FGFRs to transphosphorylate the intracellular domains. This leads to complex signaling cascades involving Ras, JAK, and other signaling pathways. Activation of Ras leads to phosphorylation and activation of either Raf or Rac. Following the Raf signaling pathway, downstream activation of ERK1/2 leads to a dichotomized transcription factors expression in the nucleus, first a group of transcription factors that limits or inhibit FGF signaling which is a negative feedback loop, or second transcription factors that promote cell proliferation. In the Rac pathway, as depicted in the diagram, phosphorylation of the Rac signal molecules leads to activation of either p38 or Jun signaling pathways, however either signaling pathways causes the expression of transcriptional factors that are associated with stress response proteins production.

The JAK signaling pathway when activated is followed by the phosphorylation of STAT, which then dimerizes and then translocated into the nucleus to potentiate the transcription of factors that ensure cell proliferation and differentiation. Other signaling cascades (not included in the diagram) also lead to the expression of factors that ensure cell survival, cell motility etc.

\subsection{IGF-1 signaling}

Salmon and Daughaday [134] identified IGF-1 and IGF-2 in 1957 and aptly named them "sulphation factor" because these factors possessed the ability to stimulate sulphate incorporation into rat cartilage [135]. In 1972 however, the coinage "sulphation factor" was replaced by the term "somatomedin", In 1976, finally, the name "insulin-like growth factor 1 and 2 (IGF 1, IGF 2) were proposed by Rinderknecht and Humbel after isolating the two active substances from human serum [136], their structural resemblance to proinsulin were the reasons behind such name branding. Following these initial studies on IGF-1, came an avalanche of investigation into the role of IGF-1 in the development of bone tissue, cartilage tissue, skin tissue, adipose tissues and so on. And while the specific and regulatory mechanisms as well as the exact stoichiometry of IGF-1 contribution to the development of these tissues are yet to be fully elucidated, much success have been achieved on understanding the major roles of IGF-1 on various developmental levels.

An in vitro assay conducted by Blunk and colleagues evidently showed that IGF-1 modulates the differentiation of bone mesenchymal stem cells into chondrocytes in spite of the absence of TGF- $\beta 1$ [137]. In this study, they measured the effects of regulatory factors on tissue-engineered cartilage with specific interest in increasing construct growth rate and the concentrations of the major extracellular matrix (ECM) components such as glycosaminoglycans (GAG) and collagen [137]. Also, in a similar study, Yang and Barabino in an in vitro experiment recorded difference in chondrocytes morphology and homogeneity of tissue-engineered cartilage in their hydrodynamic cultivation of chondrocytes with transient exposure to IGF-1 and TGF- $\beta 1$ [138].

While major milestones have been reached on IGF-1 role in cartilage formation, a shift in understanding the interactive role IGF-I and mechanical environment in modulating engineered cartilage development was carried out by Gooch and his colleagues. Their insightful finding demonstrated that the engineered tissue histologically resembled cartilage and contained its major extracellular matrix constituents such as glycosaminoglycans and collagen. Although the mechanical stimuli and IGF-I separately modulated tissue morphology, growth, biochemical composition, and equilibrium modulus of their engineered cartilage, the synergistic role of the two produced cartilage tissue with pronounced superiority to that obtained by modifying these factors individually [139].

The effect of IGF-1 deficiency on osteoarthritis severity in an animal model (Rat Knee Joints) has been investigated [g140] which clearly demonstrated the involvement of IGF-1 deficiency in heightening the severity of articular cartilage lesions of OA [140]. The necessity of IGF-1 signaling is shown to be ubiquitously required for the right development of various other tissue types, and when absent or deficient, observed developmental dysfunctions 
occurs; for instance, IGF-1 deficiency has been noted to be the underlying cause of underdevelopment and weakness of the muscular system impaired hair growth and other structural defects in patients with Laron syndrome (primary IGF-I deficiency) [141] and nail growth.

Wei and his colleagues carried out a study of exquisite simplicity and elegance that altered the understanding of the role of IGF-1, employing histological analysis, real-time PCR, and in situ hybridization of IGF-1 studies, they demonstrated that chondrocytes losses, and cartilage matrix depletion correlated with decreased IGF-1 distribution in a temporal and spatial manner [142]. Thus proving that IGF-1 serves as a protective role in osteoarthritis, they provided in vivo evidence that IGF-1 reduces the loss of chondrocytes and matrix integrity and proposed that it could be a viable target for novel therapeutic options for the management of osteoarthritis.

Despite the fact that the principles and some technical achievements are being reached, the crucial factor in translational science is the applicability of IGF-1 in cartilage disease mitigation; with these interesting findings accruing at a good pace, it is inevitable that sooner the practical utility of IGF-1 in cartilage disease management is at hand.

Signaling via IGF-1 is mediated by the binding of IGF-1 ligand to its receptor (IGF-1R), a tyrosine kinase IGF 1 receptor. This leads to the dimerization and transphosphorylation of the receptors as diagrammatically depicted in Figure 5. The phosphorylated tyrosine kinases create docking site for recruitment of insulin receptor substrate 1 (IRS 1) hence forming an IGF1R-IRS1 complex [143]. IRS 1 in turn phosphorylates to potentiate a cascade of downstream signaling [144]. Along the IGF 1 signal path are the PI3K, PDK1, AKT, mTOR to final factors such as eIF4G, P70S6K which mediate protein translation and chondrocytic hypertrophy, or the production of glycolytic enzymes [145]. Another route of IGF1 pathway is via the Shc, through to ERK as indicated in Figure 3. This route leads to the production factors that ensure chondrocytes proliferation. The second route is via the activation of Shc, that in turns activates the Grb2/SOS, Grb2/SOS activate MEK leading to the phosphorylation of ERK leading to cell proliferation [146]. 


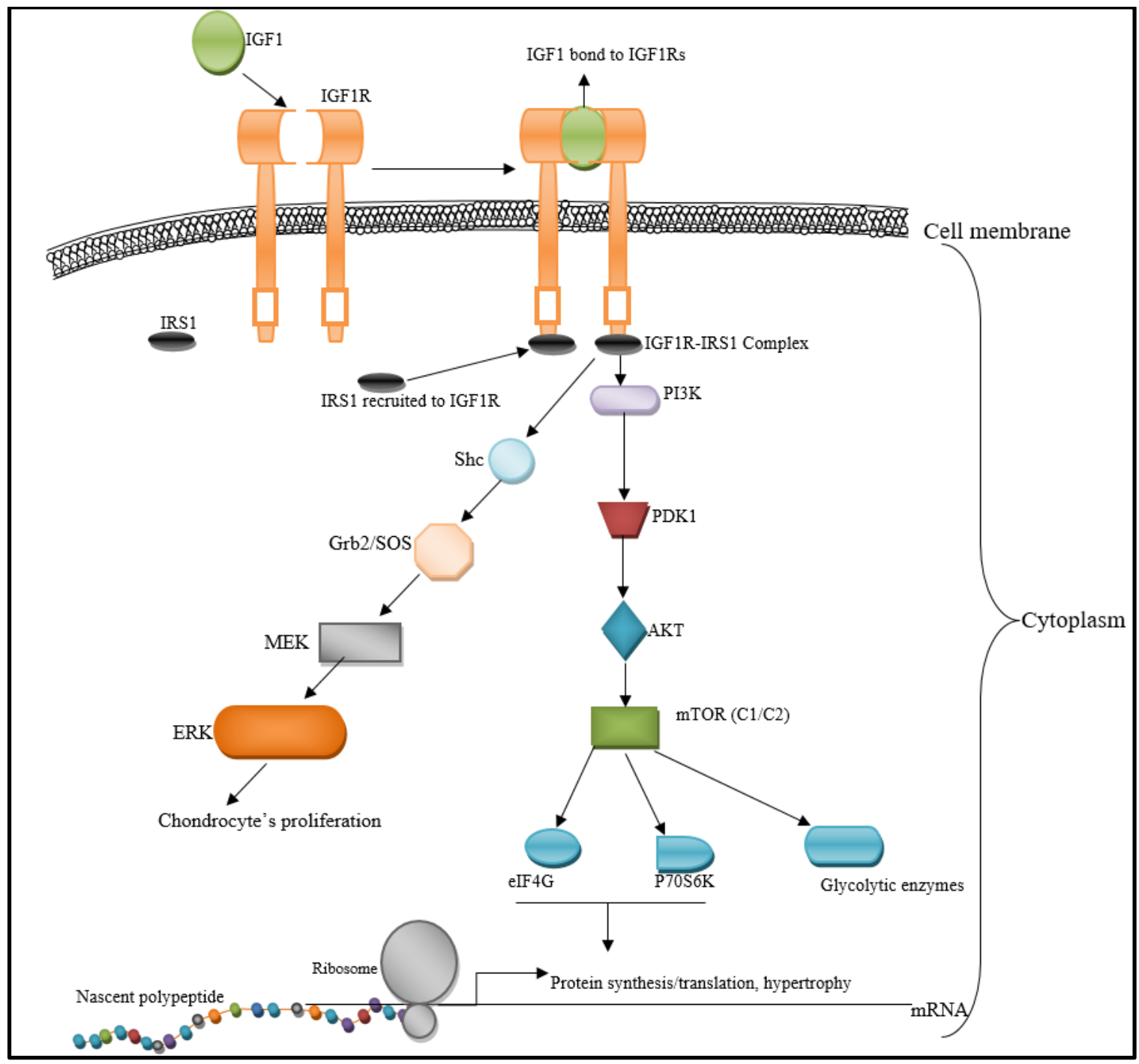

Figure 8. Graphical representation of the main IGF1 signaling pathways in chondrocyte development

Graphical representation of the main IGF1 signaling pathways; as shown, the binding of IGF1 onto IGF1R transphosphorylases the receptor, leading to dimerization and recruitment of IRS1 to form the IGF1R-IRS1 complex. Formation of this complex activates two main downstream pathways, one route is the PI3K activation which results also in the downstream activation of PDK1, which in turns phosphorylates and activate AKT leading down to the mTORs (mTORC1 or mTORC2) activation that subsequently potentiates the activation of eLF4G or P70S6K or the formation of some glycolytic enzymes [145]. The eIF4G or the P70S6K potentiate chondrocytes hypertrophy or activates the synthesis of certain protein. The second route is via the activation of Shc, that in turns activates the Grb2/SOS, Grb2/SOS activate MEK leading to the phosphorylation of ERK leading to cell proliferation [146]. 


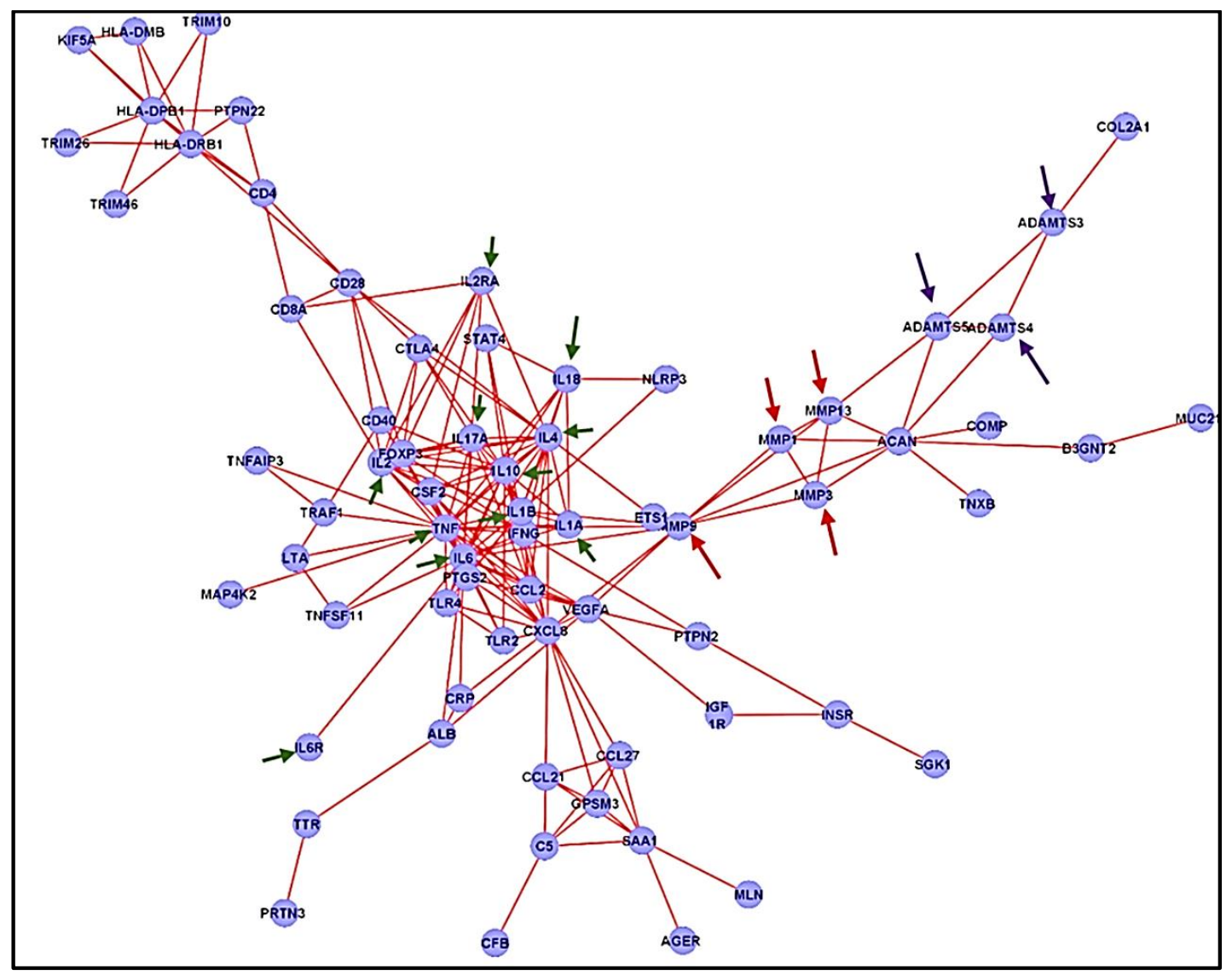

Figure 9. Signaling Networks implicated in Arthritic disease conditions. Arthritic disease interaction network, (String: PubMed query) created by Cytoscape 3.8.2. and data imported from the curated public databases with the target species being Homo sapiens only.

Under diseased microenvironmental conditions such as osteoarthritic, or rheumatoid-arthritic conditions, chondrocytes can undergo a switch in cell metabolism activate inflammatory signaling pathways and to maintain energy homeostasis [147]. As shown in Figure 9, (indicated by the green arrows) several inflammatory molecules are recruited into the diseased cartilage. The biosynthesis of inflammatory and degradative proteins such as indicated by the red and blue arrows leads to the activation of crucial transcription factors that orchestrate catabolic events in the cartilage, which eventually lead to the perpetuation and degeneration of the cartilage [148]. Osteoarthritis has been demonstrated to show increased oxidative stress and a higher expression of redox-sensitive transcription factors (e.g. NF- $\kappa B$, iNOS, IL-8 and cyclooxygenase-2 (COX-2) [149]. More so, higher ROS in cartilage tissues induces C-FOS and MMP-1 expression [150]. Cartilage degeneration usually arises from a combination of chondrocytes hypertrophy and the expression of proteolytic enzymes such as MMPs and ADAMTS that leads to the degradation of the ECM of the cartilage [151]. 


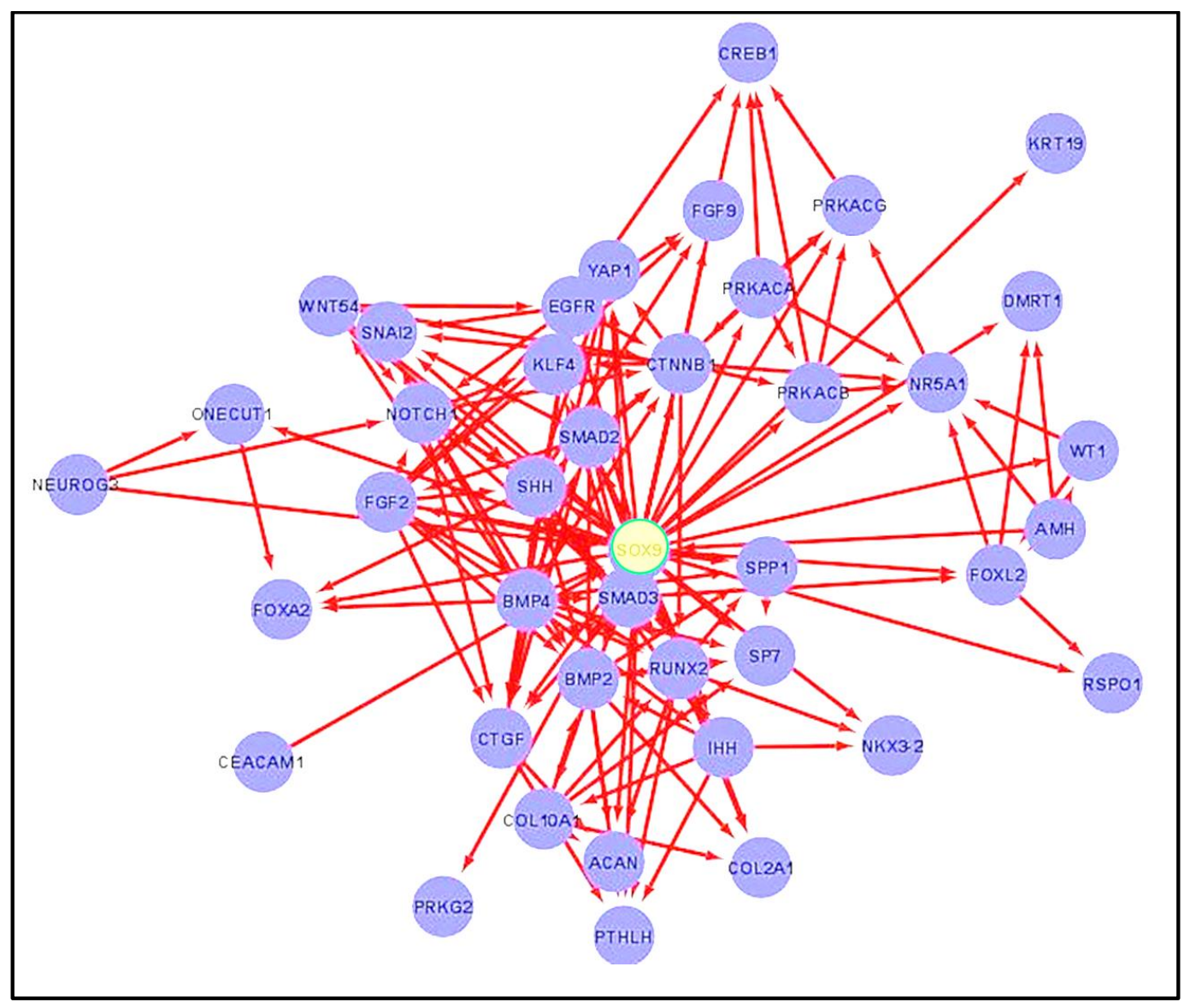

Figure 10. SOX9 interaction network, (String: PubMed query) created by Cytoscape 3.8.2. and data imported from the curated public databases with the target species being Homo sapiens only.

It is an established fact that Sox9 is a crucial protein for proper cartilage formation. This protein is therefore carefully modulated during limb organogenesis for normal chondrogenesis and joint formation processes. In a Sox 9 gain-offunction experiment performed by Lefrebvre and Crombrugghe, they demonstrated that increasing Sox 9 transcript level ( 20\%) caused dwarfism [152], and however, a 50\% downregulation in Sox9+/- mice and human campomelic dysplasia patients resulted in chondrodysplasia [153]. As shown in Figure 10, Sox9 interacts with a host of other crucial factors during chondrogenesis and for the proper formation of cartilage. Sox 9 acts as a transcriptional activator, for this reason its modification as well as the molecular interactions it have with other molecules such as shown in Figure $\mathbf{1 0}$ serve to control its transcriptional activity [154, 155]. BMP signaling has been demonstrated to regulates Sox9 expression, for instance, the inactivation of both BMPR1A and BMPR1B downregulates Sox9 expression [156]. In an in vivo kinetic analysis of the expression of chondrogenic genes e.g. Col2a1, Aggrecan, collagens, and BMP signaling components it has been demonstrated that Sox 9 expression could be induced [157]. TGF $\beta /$ BMP pathways, such as Smads and TGF $\beta$ activated kinase has been implicated in Sox9 expression during chondrogenesis [158, 159].

\subsection{Conclusion}

In conclusion, this work explored the development of cartilage, the organogenesis of the limb joint, some of the signaling cascades and transcriptional factors involved in the development of a proper cartilage. Furthermore, this review also summarized works done in cartilage related diseases and the molecular factors implicated in the etiology of such diseases. In this review also, a broader view of the unifying principles and mechanisms of signaling pathways such as FGFs, IGFs, Wnt, BMPs signaling that are crucial in chondrogenesis. In a diseased microenvironmental conditions such as osteoarthritic, or rheumatoid-arthritic conditions, chondrocytes can undergo a switch in cell metabolism activate inflammatory signaling, this study also summarizes the implications of such conditions on cartilage degeneration such as osteoarthritis and rheumatoid arthritis. 


\section{References}

1 Karuppal, R., 2017. Current concepts in the articular cartilage repair and regeneration. Journal of orthopaedics, 14(2), p.A1.

2 Houard, X., Goldring, M.B. and Berenbaum, F., 2013. Homeostatic mechanisms in articular cartilage and role of inflammation in osteoarthritis. Current rheumatology reports, 15(11), p.375.

3 Ayariga, J.A., Azumah, A.D., Deepa, B. and Dean, D., 2021. Tuning Phage for Cartilage Regeneration. In Bacteriophages. IntechOpen.

4 Sophia Fox, A.J., Bedi, A. and Rodeo, S.A., 2009. The basic science of articular cartilage: structure, composition, and function. Sports health, 1(6), pp.461-468.

5 Buckwalter, J.A. and Mankin, H.J., 1998. Articular cartilage: tissue design and chondrocyte-matrix interactions. Instructional course lectures, 47, pp.477-486.

6 Temenoff, J.S. and Mikos, A.G., 2008. Biomaterials: the intersection of biology and materials science (Vol. 1). Upper Saddle River, NJ, USA:: Pearson/Prentice Hall.

7 Şenol, M.S. and Özer, H., 2020. Architecture of cartilage tissue and its adaptation to pathological conditions. In Comparative Kinesiology of the Human Body (pp. 91-100). Academic Press.

8 Zhang, Y., Wang, F., Tan, H., Chen, G., Guo, L. and Yang, L., 2012. Analysis of the mineral composition of the human calcified cartilage zone. International journal of medical sciences, 9(5), p.353.

9 Lammi, P.E., Lammi, M.J., Hyttinen, M.M., Panula, H., Kiviranta, I. and Helminen, H.J., 2002. Site-specific immunostaining for type X collagen in noncalcified articular cartilage of canine stifle knee joint. Bone, 31(6), pp.690-696.

10 Maroudas, A., 1980. Physical chemistry of articular cartilage and the intervertebral disc. In The joints and synovial fluid (pp. 239-291). Academic Press.

11 Mow, V.C., Gu, W.Y. and Chen, F.H., 2005. Structure and function of articular cartilage and meniscus. Basic orthopaedic biomechanics and mechano-biology, 3, pp.181-258.

12 Setton, L.A., Guilak, F., Hsu, E.W. and Vail, T.P., 1999. Biomechanical factors in tissue engineered meniscal repair. Clinical Orthopaedics and Related Research®, 367, pp.S254-S272.

13 Shu-Ang Zhou, Luwei Zhou and Brahme Anders. 2014. Physical Medicine and Rehabilitation J. Watkins, in Comprehensive Biomedical Physics, pp. 13-15

14 Mandl, P., Baranauskaite, A., Damjanov, N., Hojnik, M., Kurucz, R., Nagy, O., Nemec, P., Niedermayer, D., Perić, P., Petranova, T. and Pille, A., 2016. Musculoskeletal ultrasonography in routine rheumatology practice: data from Central and Eastern European countries. Rheumatology international, 36(6), pp.845-854.

15 Maynard, R.L. and Downes, N., 2019. Anatomy and Histology of the Laboratory rat in Toxicology and Biomedical Research. Academic Press.

16 Hutmacher, D.W., Ng, K.W., Kaps, C., Sittinger, M. and Kläring, S., 2003. Elastic cartilage engineering using novel scaffold architectures in combination with a biomimetic cell carrier. Biomaterials, 24(24), pp.4445-4458.

17 Watkins, J., 2009. Pocket Podiatry: Functional Anatomy. Elsevier Health Sciences.

18 Horner, C.B., Low, K. and Nam, J., 2016. Electrospun scaffolds for cartilage regeneration. In Nanocomposites for Musculoskeletal Tissue Regeneration (pp. 213-240). Woodhead Publishing.

19 Mobasheri, A., Rayman, M.P., Gualillo, O., Sellam, J., Van Der Kraan, P. and Fearon, U., 2017. The role of metabolism in the pathogenesis of osteoarthritis. Nature Reviews Rheumatology, 13(5), pp.302-311.

20 Guo, Q., Wang, Y., Xu, D., Nossent, J., Pavlos, N.J. and Xu, J., 2018. Rheumatoid arthritis: pathological mechanisms and modern pharmacologic therapies. Bone research, 6(1), pp.1-14. 
21 van der Linden, M.P., Le Cessie, S., Raza, K., van der Woude, D., Knevel, R., Huizinga, T.W. and van der Helm-van Mil, A.H., 2010. Long-term impact of delay in assessment of patients with early arthritis. Arthritis \& Rheumatism, 62(12), pp.3537-3546.

22 Borgia, F., Giuffrida, R., Guarneri, F. and Cannavò, S.P., 2018. Relapsing polychondritis: an updated review. Biomedicines, 6(3), p.84.

23 Foidart, J.M., Abe, S., Martin, G.R., Zizic, T.M., Barnett, E.V., Lawley, T.J. and Katz, S.I., 1978. Antibodies to type II collagen in relapsing polychondritis. New England Journal of Medicine, 299(22), pp.1203-1207.

24 Pauli, R.M., 2019. Achondroplasia: a comprehensive clinical review. Orphanet Journal of Rare Diseases, 14(1), pp.1-49.

25 Schumann, J.A., Sood, T. and Parente, J.J., 2020. Costochondritis. StatPearls [Internet].

26 Proulx, A.M. and Zryd, T.W., 2009. Costochondritis: diagnosis and treatment. American family physician, 80(6), pp.617620.

27 Amin, R.M., Andrade, N.S. and Neuman, B.J., 2017. Lumbar disc herniation. Current reviews in musculoskeletal medicine, 10(4), pp.507-516.

28 Chow, W.A., 2018. Chondrosarcoma: biology, genetics, and epigenetics. F1000Research, 7.

29 Khandeparkar, S.G.S., Joshi, A., Khande, T. and Kesari, M., 2014. A rare case of giant soft tissue chondroma of the wrist: a cytopathological study with review of the literature. Journal of cytology/Indian Academy of Cytologists, 31(1), p.40.

30 Searls, R.L. and Janners, M.Y., 1971. The initiation of limb bud outgrowth in the embryonic chick. Developmental biology, 24(2), pp.198-213.

31 Chevallier, A., Kieny, M. and Mauger, A., 1977. Limb-somite relationship: origin of the limb musculature.

32 Christ, B., Jacob, H.J. and Jacob, M., 1974. Origin of wing musculature. Experimental studies on quail and chick embryos. Experientia, 30(12), pp.1446-1449.

33 Catala, M., 2000. Control of the positioning of the vertebrate limb axes during development. Morphologie: bulletin de l'Association des anatomistes, 84(265), pp.17-23.

34 Duboc, V. and Logan, M.P., 2011. Regulation of limb bud initiation and limb-type morphology. Developmental Dynamics, 240(5), pp.1017-1027.

35 Niswander, L., 2004. Interplay between the molecular signals that control vertebrate limb development. International Journal of Developmental Biology, 46(7), pp.877-881.

36 Tickle, C., 2003. Patterning systems - from one end of the limb to the other. Developmental cell, 4(4), pp.449-458.

37 Mariani, F.V. and Martin, G.R., 2003. Deciphering skeletal patterning: clues from the limb. Nature, 423(6937), pp.319-325.

38 Hill, R.E. and Lettice, L.A., 2016. Limb development. In Kaufman's Atlas of Mouse Development Supplement (pp. 193205). Academic Press.

39 Summerbell, D., Lewis, J.H. and Wolpert, L., 1973. Positional information in chick limb morphogenesis. Nature, 244(5417), pp.492-496.

40 Galloway, J.L. and Tabin, C.J., 2008. Classic limb patterning models and the work of Dennis Summerbell.

41 Chuang, P.T. and McMahon, A.P., 1999. Vertebrate Hedgehog signalling modulated by induction of a Hedgehog-binding protein. Nature, 397(6720), pp.617-621.

42 Ahn, S. and Joyner, A.L., 2004. Dynamic changes in the response of cells to positive hedgehog signaling during mouse limb patterning. Cell, 118(4), pp.505-516.

43 Geetha-Loganathan, P., Nimmagadda, S. and Scaal, M., 2008. Wnt signaling in limb organogenesis. Organogenesis, 4(2), pp.109-115.

44 Karaplis, A.C., 2008. Embryonic development of bone and regulation of intramembranous and endochondral bone formation. Principles of bone biology, pp.53-84. 
45 Logan, Cairine, Amata Hornbruch, Iano Campbell, and Andrew Lumsden. "The role of Engrailed in establishing the dorsoventral axis of the chick limb." Development 124, no. 12 (1997): 2317-2324.

46 Rivadeneira, F. and Uitterlinden, A.G., 2018. Osteoporosis genes identified by genome-wide association studies. In Genetics of Bone Biology and Skeletal Disease. pp. 377-395. Academic Press.

47 Kabak, S. and Boizow, L., 1990. Organogenesis of the limb skeleton and the limb joints in the human embryo. Anatomischer Anzeiger, 170(5), pp.349-357.

48 Bossy, J., 1982. Sequence of development of cutaneous innervation of the limbs in the human embryo. Bulletin de l'Association des anatomistes, 66(192), pp.57-61.

49 Pacifici, M., Koyama, E., Shibukawa, Y., Wu, C., Tamamura, Y., Enomoto-Iwamoto, M. and Iwamoto, M., 2006. Cellular and molecular mechanisms of synovial joint and articular cartilage formation. Annals of the New York Academy of Sciences, 1068 , p.74.

50 Tabin, C. and Wolpert, L., 2007. Rethinking the proximodistal axis of the vertebrate limb in the molecular era. Genes $\mathcal{E}$ development, 21(12), pp.1433-1442.

51 ten Berge, D., Brugmann, S.A., Helms, J.A. and Nusse, R., 2008. Wnt and FGF signals interact to coordinate growth with cell fate specification during limb development.

52 Archer, C.W., Dowthwaite, G.P. and Francis-West, P., 2003. Development of synovial joints. Birth Defects Research Part C: Embryo Today: Reviews, 69(2), pp.144-155.

53 Hinchliffe, J.R. and Johnson, D.R., 1980. Experimental embryology. The development of the vertebrate limb. New York: Oxford University Press. p, pp.109-147.

54 Lamb, K.J., Lewthwaite, J.C., Bastow, E.R. and Pitsillides, A.A., 2003. Defining boundaries during joint cavity formation: going out on a limb. International journal of experimental pathology, 84(2), pp.55-67.

55 Wescoe, K.E., Schugar, R.C., Chu, C.R. and Deasy, B.M., 2008. The role of the biochemical and biophysical environment in chondrogenic stem cell differentiation assays and cartilage tissue engineering. Cell biochemistry and biophysics, 52(2), pp.85-102.

56 Lelkes, G., 1958. Experiments in vitro on the role of movement in the development of joints.

57 Drachman, D.B. and Sokoloff, L., 1966. The role of movement in embryonic joint development. Developmental Biology, 14(3), pp.401-420.

58 Edwards, J.C., Wilkinson, L.S., Jones, H.M., Soothill, P., Henderson, K.J., Worrall, J.G. and Pitsillides, A.A., 1994. The formation of human synovial joint cavities: a possible role for hyaluronan and CD44 in altered interzone cohesion. Journal of anatomy, 185(Pt 2), p.355.

59 Hall, B.K. and Miyake, T., 2000. All for one and one for all: condensations and the initiation of skeletal development. Bioessays, 22(2), pp.138-147.

60 Osborne, A.C., Lamb, K.J., Lewthwaite, J.C., Dowthwaite, G.P. and Pitsillides, A.A., 2002. Short-term rigid and flaccid paralyses diminish growth of embryonic chick limbs and abrogate joint cavity formation but differentially preserve precavitated joints. Journal of Musculoskeletal and Neuronal Interactions, 2(5), pp.448-456.

61 Decker, R.S., Koyama, E. and Pacifici, M., 2014. Genesis and morphogenesis of limb synovial joints and articular cartilage. Matrix Biology, 39, pp.5-10.

62 Hyde, G., Dover, S., Aszodi, A., Wallis, G.A. and Boot-Handford, R.P., 2007. Lineage tracing using matrilin-1 gene expression reveals that articular chondrocytes exist as the joint interzone forms. Developmental biology, 304(2), pp.825833.

63 Hyde, G., Boot-Handford, R.P. and Wallis, G.A., 2008. Col2a1 lineage tracing reveals that the meniscus of the knee joint has a complex cellular origin. Journal of anatomy, 213(5), pp.531-538. 
64 Jenner, F., IJpma, A., Cleary, M., Heijsman, D., Narcisi, R., van der Spek, P.J., Kremer, A., van Weeren, R., Brama, P. and van Osch, G.J., 2014. Differential gene expression of the intermediate and outer interzone layers of developing articular cartilage in murine embryos. Stem cells and development, 23(16), pp.1883-1898.

65 Naganathan, S.R. and Oates, A.C., 2017. Mechanochemical coupling and developmental pattern formation. Current Opinion in Systems Biology, 5, pp.104-111.

66 Guilak, F., Butler, D.L., Goldstein, S.A. and Baaijens, F.P., 2014. Biomechanics and mechanobiology in functional tissue engineering. Journal of biomechanics, 47(9), pp.1933-1940.

67 Mikic, B., Johnson, T.L., Chhabra, A.B., Schalet, B.J., Wong, M. and Hunziker, E.B., 2000. Differential effects of embryonic immobilization on the development of fibrocartilaginous skeletal elements. Journal of rehabilitation research and development, 37(2), pp.127-134.

68 Mammoto, A., Mammoto, T. and Ingber, D.E., 2012. Mechanosensitive mechanisms in transcriptional regulation. Journal of cell science, 125(13), pp.3061-3073.

69 Tiku, M.L. and Sabaawy, H.E., 2015. Cartilage regeneration for treatment of osteoarthritis: a paradigm for nonsurgical intervention. Therapeutic advances in musculoskeletal disease, 7(3), pp.76-87.

70 Degen, K.E. and Gourdie, R.G., 2012. Embryonic wound healing: a primer for engineering novel therapies for tissue repair. Birth Defects Research Part C: Embryo Today: Reviews, 96(3), pp.258-270.

71 Wodarz, A. and Nusse, R., 1998. Mechanisms of Wnt signaling in development. Annual review of cell and developmental biology, 14(1), pp.59-88.

72 Croce, J.C. and McClay, D.R., 2006, April. The canonical Wnt pathway in embryonic axis polarity. In Seminars in cell E developmental biology (Vol. 17, No. 2, pp. 168-174). Academic Press.

73 Blagodatski, A., Poteryaev, D. and Katanaev, V.L., 2014. Targeting the Wnt pathways for therapies. Molecular and cellular therapies, 2(1), pp.1-15.

74 Daniels, D.L. and Weis, W.I., 2002. ICAT inhibits $\beta$-catenin binding to Tcf/Lef-family transcription factors and the general coactivator p300 using independent structural modules. Molecular cell, 10(3), pp.573-584.

75 Schuijers, J., Mokry, M., Hatzis, P., Cuppen, E. and Clevers, H., 2014. Wnt-induced transcriptional activation is exclusively mediated by TCF/LEF. The EMBO journal, 33(2), pp.146-156.

76 Logan, C.Y. and Nusse, R., 2004. The Wnt signaling pathway in development and disease. Annu. Rev. Cell Dev. Biol., 20, pp.781-810.

77 Huelsken, J. and Birchmeier, W., 2001. New aspects of Wnt signaling pathways in higher vertebrates. Current opinion in genetics \& development, 11(5), pp.547-553.

78 Nusse, R., 2005. Wnt signaling in disease and in development. Cell research, 15(1), pp.28-32.

79 Agarwal, P., Wylie, J.N., Galceran, J., Arkhitko, O., Li, C., Deng, C., Grosschedl, R. and Bruneau, B.G., 2003. Tbx5 is essential for forelimb bud initiation following patterning of the limb field in the mouse embryo.

80 Hartmann, C. and Tabin, C.J., 2000. Dual roles of Wnt signaling during chondrogenesis in the chicken limb. Development, 127(14), pp.3141-3159.

81 Guo, X., Day, T.F., Jiang, X., Garrett-Beal, L., Topol, L. and Yang, Y., 2004. Wnt/ $\beta$-catenin signaling is sufficient and necessary for synovial joint formation. Genes \& development, 18(19), pp.2404-2417.

82 Hill, T.P., Später, D., Taketo, M.M., Birchmeier, W. and Hartmann, C., 2005. Canonical Wnt/ $\beta$-catenin signaling prevents osteoblasts from differentiating into chondrocytes. Developmental cell, 8(5), pp.727-738.

83 Sen, M., Reifert, J., Lauterbach, K., Wolf, V., Rubin, J.S., Corr, M. and Carson, D.A., 2002. Regulation of fibronectin and metalloproteinase expression by Wnt signaling in rheumatoid arthritis synoviocytes. Arthritis \& Rheumatism: Official Journal of the American College of Rheumatology, 46(11), pp.2867-2877. 
84 van den Bosch, M.H., Blom, A.B., van de Loo, F.A., Koenders, M.I., Lafeber, F.P., Van Den Berg, W.B., van der Kraan, P.M. and van Lent, P.L., 2017. Brief report: induction of matrix metalloproteinase expression by synovial wnt signaling and association with disease progression in early symptomatic osteoarthritis. Arthritis \& Rheumatology, 69(10), pp.19781983.

85 Funck-Brentano, T., Bouaziz, W., Marty, C., Geoffroy, V., Hay, E. and Cohen-Solal, M., 2014. Dkk-1-Mediated Inhibition of Wnt Signaling in Bone Ameliorates Osteoarthritis in Mice. Arthritis \& rheumatology, 66(11), pp.3028-3039.

86 Abed, É., Couchourel, D., Delalandre, A., Duval, N., Pelletier, J.P., Martel-Pelletier, J. and Lajeunesse, D., 2014. Low sirtuin 1 levels in human osteoarthritis subchondral osteoblasts lead to abnormal sclerostin expression which decreases Wnt/ $\beta$-catenin activity. Bone, 59, pp.28-36.

87 Chan, B.Y. and Little, C.B., 2012. The interaction of canonical bone morphogenetic protein-and Wnt-signaling pathways may play an important role in regulating cartilage degradation in osteoarthritis.

88 Sellers, R.S., Zhang, R., Glasson, S.S., Kim, H.D., Peluso, D., D'AUGUSTA, D.A., Beckwith, K. and Morris, E.A., 2000. Repair of articular cartilage defects one year after treatment with recombinant human bone morphogenetic protein-2 (rhBMP-2). JBJS, 82(2), pp.151-60.

89 Michielsen, J., Sys, J., Rigaux, A. and Bertrand, C., 2013. The effect of recombinant human bone morphogenetic protein-2 in single-level posterior lumbar interbody arthrodesis. JBJS, 95(10), pp.873-880.

90 Gomez-Puerto, M.C., Iyengar, P.V., García de Vinuesa, A., Ten Dijke, P. and Sanchez-Duffhues, G., 2019. Bone morphogenetic protein receptor signal transduction in human disease. The journal of pathology, 247(1), pp.9-20.

91 Abdurahman, A., Du, X., Yao, Y., Sulaiman, Y., Aniwashi, J. and Li, Q., 2019. Smad4 feedback enhances BMPR1B transcription in ovine granulosa cells. International journal of molecular sciences, 20(11), p.2732.

92 Beederman, M., Lamplot, J.D., Nan, G., Wang, J., Liu, X., Yin, L., Li, R., Shui, W., Zhang, H., Kim, S.H. and Zhang, W., 2013. BMP signaling in mesenchymal stem cell differentiation and bone formation. Journal of biomedical science and engineering, 6(8A), p.32.

93 Brunet, L.J., McMahon, J.A., McMahon, A.P. and Harland, R.M., 1998. Noggin, cartilage morphogenesis, and joint formation in the mammalian skeleton. Science, 280(5368), pp.1455-1457.

94 Kamiya, N., Kobayashi, T., Mochida, Y., Yu, P.B., Yamauchi, M., Kronenberg, H.M. and Mishina, Y., 2010. Wnt inhibitors Dkk1 and Sost are downstream targets of BMP signaling through the type IA receptor (BMPRIA) in osteoblasts. Journal of Bone and Mineral Research, 25(2), pp.200-210.

95 Varady, P., Li, J.Z., Alden, T.D., Kallmes, D.F., Williams, M.B. and Helm, G.A., 2002. CT and radionuclide study of BMP2 gene therapy-induced bone formation. Academic radiology, 9(6), pp.632-637.

96 Van der Kraan, P.M., Davidson, E.B. and van Den Berg, W.B., 2010. Bone morphogenetic proteins and articular cartilage: to serve and protect or a wolf in sheep clothing's?. Osteoarthritis and cartilage, 18(6), pp.735-741.

97 Armelin, H.A., 1973. Pituitary extracts and steroid hormones in the control of 3T3 cell growth. Proceedings of the National Academy of Sciences, 70(9), pp.2702-2706.

98 Gospodarowicz, D., 1974. Localisation of a fibroblast growth factor and its effect alone and with hydrocortisone on 3T3 cell growth. Nature, 249(5453), pp.123-127.

99 Basilico, C. and Moscatelli, D., 1992. The FGF family of growth factors and oncogenes. Advances in cancer research, 59, pp.115-165.

100 Baird, A., 1994. Fibroblast growth factors: activities and significance of non-neurotrophin neurotrophic growth factors. Current opinion in neurobiology, 4(1), pp.78-86.

101 Dorey, K. and Amaya, E., 2010. FGF signalling: diverse roles during early vertebrate embryogenesis. Development, 137(22), pp.3731-3742. 
102 Green, J.D., Tollemar, V., Dougherty, M., Yan, Z., Yin, L., Ye, J., Collier, Z., Mohammed, M.K., Haydon, R.C., Luu, H.H. and Kang, R., 2015. Multifaceted signaling regulators of chondrogenesis: implications in cartilage regeneration and tissue engineering. Genes \& diseases, 2(4), pp.307-327.

103 Ornitz, D.M. and Itoh, N., 2015. The fibroblast growth factor signaling pathway. Wiley Interdisciplinary Reviews: Developmental Biology, 4(3), pp.215-266.

104 Goetz, R. and Mohammadi, M., 2013. Exploring mechanisms of FGF signalling through the lens of structural biology. Nature reviews Molecular cell biology, 14(3), pp.166-180.

105 Goetz, R., Dover, K., Laezza, F., Shtraizent, N., Huang, X., Tchetchik, D., Eliseenkova, A.V., Xu, C.F., Neubert, T.A., Ornitz, D.M. and Goldfarb, M., 2009. Crystal structure of a fibroblast growth factor homologous factor (FHF) defines a conserved surface on FHFs for binding and modulation of voltage-gated sodium channels. Journal of Biological Chemistry, 284(26), pp.17883-17896.

106 Ornitz, D.M. and Marie, P.J., 2015. Fibroblast growth factor signaling in skeletal development and disease. Genes \& development, 29(14), pp.1463-1486.

107 Mercader, N., Leonardo, E., Piedra, M.E., Martinez-A, C., Ros, M.A. and Torres, M., 2000. Opposing RA and FGF signals control proximodistal vertebrate limb development through regulation of Meis genes. Development, 127(18), pp.39613970.

108 Ornitz, D.M., 2000. FGFs, heparan sulfate and FGFRs: complex interactions essential for development. Bioessays, 22(2), pp.108-112.

109 Umemori, H., Linhoff, M.W., Ornitz, D.M. and Sanes, J.R., 2004. FGF22 and its close relatives are presynaptic organizing molecules in the mammalian brain. Cell, 118(2), pp.257-270.

110 Wu, X.L., Gu, M.M., Huang, L., Liu, X.S., Zhang, H.X., Ding, X.Y., Xu, J.Q., Cui, B., Wang, L., Lu, S.Y. and Chen, X.Y., 2009. Multiple synostoses syndrome is due to a missense mutation in exon 2 of FGF9 gene. The American Journal of Human Genetics, 85(1), pp.53-63.

111 Qu, X., Pan, Y., Carbe, C., Powers, A., Grobe, K. and Zhang, X., 2012. Glycosaminoglycan-dependent restriction of FGF diffusion is necessary for lacrimal gland development. Development, 139(15), pp.2730-2739.

112 Martin, G.R., 1998. The roles of FGFs in the early development of vertebrate limbs. Genes \& development, 12(11), pp.1571-1586.

113 Barrow, J.R., Thomas, K.R., Boussadia-Zahui, O., Moore, R., Kemler, R., Capecchi, M.R. and McMahon, A.P., 2003. Ectodermal Wnt3/ $\beta$-catenin signaling is required for the establishment and maintenance of the apical ectodermal ridge. Genes \& development, 17(3), pp.394-409.

114 Ohuchi, H., Nakagawa, T., Yamamoto, A., Araga, A., Ohata, T., Ishimaru, Y., Yoshioka, H., Kuwana, T., Nohno, T., Yamasaki, M. and Itoh, N., 1997. The mesenchymal factor, FGF10, initiates and maintains the outgrowth of the chick limb bud through interaction with FGF8, an apical ectodermal factor. Development, 124(11), pp.2235-2244.

115 Kim, W.S. and Stocum, D.L., 1986. Retinoic acid modifies positional memory in the anteroposterior axis of regenerating axolotl limbs. Developmental biology, 114(1), pp.170-179.

116 Cunningham, T.J. and Duester, G., 2015. Mechanisms of retinoic acid signalling and its roles in organ and limb development. Nature reviews Molecular cell biology, 16(2), pp.110-123.

117 Beenken, A. and Mohammadi, M., 2009. The FGF family: biology, pathophysiology and therapy. Nature reviews Drug discovery, 8(3), pp.235-253.

118 Handorf, A.M. and Li, W.J., 2011. Fibroblast growth factor-2 primes human mesenchymal stem cells for enhanced chondrogenesis. PloS one, 6(7), p.e22887. 
119 Solchaga, L.A., Penick, K., Porter, J.D., Goldberg, V.M., Caplan, A.I. and Welter, J.F., 2005. FGF-2 enhances the mitotic and chondrogenic potentials of human adult bone marrow-derived mesenchymal stem cells. Journal of cellular physiology, 203(2), pp.398-409.

120 Ito, T., Sawada, R., Fujiwara, Y. and Tsuchiya, T., 2008. FGF-2 increases osteogenic and chondrogenic differentiation potentials of human mesenchymal stem cells by inactivation of TGF- $\beta$ signaling. Cytotechnology, 56(1), pp.1-7.

121 Stevens, M.M., Marini, R.P., Martin, I., Langer, R. and Shastri, V.P., 2004. FGF-2 enhances TGF- $\beta 1$-induced periosteal chondrogenesis. Journal of orthopaedic research, 22(5), pp.1114-1119.

122 Richter, W., Bock, R., Hennig, T. and Weiss, S., 2009, September. Influence of FGF-2 and PTHrP on chondrogenic differentiation of human mesenchymal stem cells. In Orthopaedic Proceedings (Vol. 91, No. SUPP_III, pp. 444-444). The British Editorial Society of Bone \& Joint Surgery.

123 Narcisi, R., Cleary, M.A., Brama, P.A., Hoogduijn, M.J., Tüysüz, N., ten Berge, D. and van Osch, G.J., 2015. Long-term expansion, enhanced chondrogenic potential, and suppression of endochondral ossification of adult human MSCs via WNT signaling modulation. Stem cell reports, 4(3), pp.459-472.

124 Ng, F., Boucher, S., Koh, S., Sastry, K.S., Chase, L., Lakshmipathy, U., Choong, C., Yang, Z., Vemuri, M.C., Rao, M.S. and Tanavde, V., 2008. PDGF, TGF- $\beta$, and FGF signaling is important for differentiation and growth of mesenchymal stem cells (MSCs): transcriptional profiling can identify markers and signaling pathways important in differentiation of MSCs into adipogenic, chondrogenic, and osteogenic lineages. Blood, The Journal of the American Society of Hematology, 112(2), pp.295-307.

125 Lemmon, S.K. and Bradshaw, R.A., 1983. Purification and partial characterization of bovine pituitary fibroblast growth factor. Journal of cellular biochemistry, 21(3), pp.195-208.

126 Prudovsky, Igor, Thallapuranam Krishnaswamy Suresh Kumar, Sarah Sterling, and David Neivandt. "Proteinphospholipid interactions in nonclassical protein secretion: problem and methods of study." International journal of molecular sciences 14, no. 2 (2013): 3734-3772.

127 Prudovsky, I., Mandinova, A., Soldi, R., Bagala, C., Graziani, I., Landriscina, M., Tarantini, F., Duarte, M., Bellum, S., Doherty, H. and Maciag, T., 2003. The non-classical export routes: FGF1 and IL-1 $\alpha$ point the way. Journal of cell science, 116(24), pp.4871-4881.

128 Landriscina, M., Soldi, R., Bagalá, C., Micucci, I., Bellum, S., Tarantini, F., Prudovsky, I. and Maciag, T., 2001. S100A13 participates in the release of fibroblast growth factor 1 in response to heat shock in vitro. Journal of Biological Chemistry, 276(25), pp.22544-22552.

129 Bouleau, S., Grimal, H., Rincheval, V., Godefroy, N., Mignotte, B., Vayssiere, J.L. and Renaud, F., 2005. FGF1 inhibits p53-dependent apoptosis and cell cycle arrest via an intracrine pathway. Oncogene, 24(53), pp.7839-7849.

130 Rodriguez-Enfedaque, A., Bouleau, S., Laurent, M., Courtois, Y., Mignotte, B., Vayssière, J.L. and Renaud, F., 2009. FGF1 nuclear translocation is required for both its neurotrophic activity and its p53-dependent apoptosis protection. Biochimica et Biophysica Acta (BBA)-Molecular Cell Research, 1793(11), pp.1719-1727.

131 Dai, J., Wang, J., Lu, J., Zou, D., Sun, H., Dong, Y., Yu, H., Zhang, L., Yang, T., Zhang, X. and Wang, X., 2012. The effect of co-culturing costal chondrocytes and dental pulp stem cells combined with exogenous FGF9 protein on chondrogenesis and ossification in engineered cartilage. Biomaterials, 33(31), pp.7699-7711.

132 Correa, D., Somoza, R.A., Lin, P., Greenberg, S., Rom, E., Duesler, L., Welter, J.F., Yayon, A. and Caplan, A.I., 2015. Sequential exposure to fibroblast growth factors (FGF) 2, 9 and 18 enhances hMSC chondrogenic differentiation. Osteoarthritis and Cartilage, 23(3), pp.443-453. 
133 Moore, E.E., Bendele, A.M., Thompson, D.L., Littau, A., Waggie, K.S., Reardon, B. and Ellsworth, J.L., 2005. Fibroblast growth factor-18 stimulates chondrogenesis and cartilage repair in a rat model of injury-induced osteoarthritis. Osteoarthritis and cartilage, 13(7), pp.623-631.

134 Salmon, W.D. and Daughaday, W.H., 1990. A hormonally controlled serum factor which stimulates sulfate incorporation by cartilage in vitro. The Journal of laboratory and clinical medicine, 116(3), pp.408-419.

135 Laron, Z., Pertzelan, A., Karp, M., Kowadlo-Silbergeld, A. and Daughaday, W.H., 1971. Administration of growth hormone to patients with familial dwarfism with high plasma immunoreactive growth hormone: measurement of sulfation factor, metabolic and linear growth responses. The Journal of Clinical Endocrinology \& Metabolism, 33(2), pp.332-342.

136 Rinderknecht, E. and Humbel, R.E., 1976. Polypeptides with nonsuppressible insulin-like and cell-growth promoting activities in human serum: isolation, chemical characterization, and some biological properties of forms I and II. Proceedings of the National Academy of Sciences, 73(7), pp.2365-2369.

137 Blunk, T., Sieminski, A.L., Gooch, K.J., Courter, D.L., Hollander, A.P., Nahir, A.M., Langer, R., Vunjak-Novakovic, G. and Freed, L.E., 2002. Differential effects of growth factors on tissue-engineered cartilage. Tissue engineering, 8(1), pp.7384.

138 Yang, Y.H. and Barabino, G.A., 2013. Differential morphology and homogeneity of tissue-engineered cartilage in hydrodynamic cultivation with transient exposure to insulin-like growth factor-1 and transforming growth factor- $\beta 1$. Tissue Engineering Part A, 19(21-22), pp.2349-2360.

139 Gooch, K.J., Blunk, T., Courter, D.L., Sieminski, A.L., Bursac, P.M., Vunjak-Novakovic, G. and Freed, L.E., 2001. IGFI and mechanical environment interact to modulate engineered cartilage development. Biochemical and biophysical research communications, 286(5), pp.909-915.

140 Ekenstedt, K.J., Sonntag, W.E., Loeser, R.F., Lindgren, B.R. and Carlson, C.S., 2006. Effects of chronic growth hormone and insulin-like growth factor 1 deficiency on osteoarthritis severity in rat knee joints. Arthritis \& Rheumatism: Official Journal of the American College of Rheumatology, 54(12), pp.3850-3858.

141 Lurie, R., Ben-Amitai, D. and Laron, Z., 2003, June. Impaired hair growth and structural defects in patients with Laron syndrome (primary IGF-I deficiency). In The Journal of Investigative Dermatology Symposium Proceedings (Vol. 8).

142 Wei, F.Y., Lee, J.K., Wei, L., Qu, F. and Zhang, J.Z., 2017. Correlation of insulin-like growth factor 1 and osteoarthritic cartilage degradation: a spontaneous osteoarthritis in guinea-pig. European review for medical and pharmacological sciences, 21(20), p.4493.

143 Böhni, R., Riesgo-Escovar, J., Oldham, S., Brogiolo, W., Stocker, H., Andruss, B.F., Beckingham, K. and Hafen, E., 1999. Autonomous control of cell and organ size by CHICO, a Drosophila homolog of vertebrate IRS1-4. Cell, 97(7), pp.865875 .

144 Haruta, T., Uno, T., Kawahara, J., Takano, A., Egawa, K., Sharma, P.M., Olefsky, J.M. and Kobayashi, M., 2000. A rapamycin-sensitive pathway down-regulates insulin signaling via phosphorylation and proteasomal degradation of insulin receptor substrate-1. Molecular endocrinology, 14(6), pp.783-794.

145 Egerman, M.A. and Glass, D.J., 2014. Signaling pathways controlling skeletal muscle mass. Critical reviews in biochemistry and molecular biology, 49(1), pp.59-68.

146 Guntur, A.R. and Rosen, C.J., 2013. IGF-1 regulation of key signaling pathways in bone. BoneKEy reports, 2. 
147 Mobasheri, A., Rayman, M.P., Gualillo, O., Sellam, J., Van Der Kraan, P. and Fearon, U., 2017. The role of metabolism in the pathogenesis of osteoarthritis. Nature Reviews Rheumatology, 13(5), pp.302-311.

148 Yin, W., Park, J.I. and Loeser, R.F., 2009. Oxidative stress inhibits insulin-like growth factor-I induction of chondrocyte proteoglycan synthesis through differential regulation of phosphatidylinositol 3-Kinase-Akt and MEK-ERK MAPK signaling pathways. Journal of Biological Chemistry, 284(46), pp.31972-31981.

149 Lepetsos, P. and Papavassiliou, A.G., 2016. ROS/oxidative stress signaling in osteoarthritis. Biochimica et Biophysica Acta (BBA)-Molecular Basis of Disease, 1862(4), pp.576-591.

150 Lo, Y.Y., Conquer, J.A., Grinstein, S. and Cruz, T.F., 1998. Interleukin-1 $\beta$ induction of c-fos and collagenase expression in articular chondrocytes: Involvement of reactive oxygen species. Journal of cellular biochemistry, 69(1), pp.19-29.

151 Akkiraju, H. and Nohe, A., 2015. Role of chondrocytes in cartilage formation, progression of osteoarthritis and cartilage regeneration. Journal of developmental biology, 3(4), pp.177-192.

152 Lefrebvre, V. and de Crombrugghe, B., 1998. Toward understanding S0X9 function in chondrocyte differentiation. Matrix biology, 16(9), pp.529-540.

153 Bi, W., Huang, W., Whitworth, D.J., Deng, J.M., Zhang, Z., Behringer, R.R. and De Crombrugghe, B., 2001. Haploinsufficiency of Sox9 results in defective cartilage primordia and premature skeletal mineralization. Proceedings of the National Academy of Sciences, 98(12), pp.6698-6703.

154 Kawakami, Y., Rodriguez-León, J. and Belmonte, J.C.I., 2006. The role of TGF $\beta$ s and Sox9 during limb chondrogenesis. Current opinion in cell biology, 18(6), pp.723-729.

155 Goldring, M.B., Tsuchimochi, K. and Ijiri, K., 2006. The control of chondrogenesis. Journal of cellular biochemistry, 97(1), pp.33-44.

156 Yoon, B.S., Ovchinnikov, D.A., Yoshii, I., Mishina, Y., Behringer, R.R. and Lyons, K.M., 2005. Bmpr1a and Bmpr1b have overlapping functions and are essential for chondrogenesis in vivo. Proceedings of the National Academy of Sciences, 102(14), pp.5062-5067.

157 Chimal-Monroy, J., Rodriguez-Leon, J., Montero, J.A., Ganan, Y., Macias, D., Merino, R. and Hurle, J.M., 2003. Analysis of the molecular cascade responsible for mesodermal limb chondrogenesis: Sox genes and BMP signaling. Developmental biology, 257(2), pp.292-301.

158 Yoon, B.S. and Lyons, K.M., 2004. Multiple functions of BMPs in chondrogenesis. Journal of cellular biochemistry, 93(1), pp.93-103.

159 Wan, M. and Cao, X., 2005. BMP signaling in skeletal development. Biochemical and biophysical research communications, 328(3), pp.651-657. 